\title{
Statistical study of high-latitude plasma flow during magnetospheric substorms
}

\author{
G. Provan ${ }^{1}$, M. Lester ${ }^{1}$, S. B. Mende ${ }^{2}$, and S. E. Milan ${ }^{1}$ \\ ${ }^{1}$ Department of Physics and Astronomy, University of Leicester, University Road, Leicester, LE1 7RH, UK \\ ${ }^{2}$ Space Science Laboratory, University of California, Berkeley, California, USA
}

Received: 9 October 2003 - Revised: 18 June 2004 - Accepted: 24 June 2004 - Published: 3 November 2004

\begin{abstract}
We have utilised the near-global imaging capabilities of the Northern Hemisphere SuperDARN radars, to perform a statistical superposed epoch analysis of high-latitude plasma flows during magnetospheric substorms. The study involved 67 substorms, identified using the IMAGE FUV space-borne auroral imager. A substorm co-ordinate system was developed, centred on the magnetic local time and magnetic latitude of substorm onset determined from the auroral images. The plasma flow vectors from all 67 intervals were combined, creating global statistical plasma flow patterns and backscatter occurrence statistics during the substorm growth and expansion phases. The commencement of the substorm growth phase was clearly observed in the radar data 18-20 min before substorm onset, with an increase in the anti-sunward component of the plasma velocity flowing across dawn sector of the polar cap and a peak in the dawnto-dusk transpolar voltage. Nightside backscatter moved to lower latitudes as the growth phase progressed. At substorm onset a flow suppression region was observed on the nightside, with fast flows surrounding the suppressed flow region. The dawn-to-dusk transpolar voltage increased from $\sim 40 \mathrm{kV}$ just before substorm onset to $\sim 75 \mathrm{kV} 12 \mathrm{~min}$ after onset. The low-latitude return flow started to increase at substorm onset and continued to increase until $8 \mathrm{~min}$ after onset. The velocity flowing across the polar-cap peaked 12-14 min after onset. This increase in the flux of the polar cap and the excitation of large-scale plasma flow occurred even though the IMF $B_{z}$ component was increasing (becoming less negative) during most of this time. This study is the first to statistically prove that nightside reconnection creates magnetic flux and excites high-latitude plasma flow in a similar way to dayside reconnection and that dayside and nightside reconnection, are two separate time-dependent processes.
\end{abstract}

Key words. Magnetospheric physics (Storms and Substorms, plasma convection) - Ionosphere (plasma convection)

\section{Correspondence to: G. Provan}

(gp3@ion.le.ac.uk)

\section{Introduction}

The two-cell convection pattern observed in the high-latitude ionosphere was initially explained by Dungey's (1961) reconnection cycle. Dungey (1961) stated that during periods of southward interplanetary magnetic field (IMF), reconnection at the dayside magnetopause would lead to the creation of open magnetic flux in the Earth's polar cap. This open magnetic flux would convect over the poles and then be closed by reconnection processes on the nightside in the magnetotail. This circulation of magnetic flux was originally assumed to be a steady-state phenomenon, with the rate of creation and destruction of open flux being equal at any one instance of time. Russell (1972) sketched the ionospheric flows resulting from a non-steady substorm cycle; reconnection on the dayside and in the tail became viewed as two separate time-dependent processes, resulting in nonsteady plasma flow in the high-latitude ionosphere (Russell and McPherron, 1973; Siscoe and Huang, 1985; Lockwood et al., 1990, Cowley and Lockwood, 1992).

Freeman and Southwood (1988) discussed the flows generated by the localized addition of flux to the dayside polar cap, and the subsequent reconfiguration of the polar cap boundary. Both reconnection at the dayside magnetopause and in the tail generates ionospheric convection. Figure 1a (after Lockwood et al., 1990, Lockwood, 1991) describes steady-state flow driven by balanced dayside and nightside reconnection. The solid-line corresponds to the open/closed field line boundary and the dashed line to the dayside or nightside merging gap, that is the ionospheric projection of the reconnection line. $\Phi_{D}$ corresponds to the potential across the dayside merging gap, $\Phi_{N}$ to the potential across the nightside merging gap and $\Phi_{p c}$ to the cross polar-cap potential. Reconnection on either the dayside or the nightside influences convection at all locations within the polar cap and auroral ovals (Lockwood, 1991). Figure 1b shows the convection pattern generated by reconnection at the magnetopause alone. Purely dayside reconnection leads to the creation of open flux, and the subsequent expansion of the polar cap. The flows are expected to be strongest on the dayside, with the foci of the twin-vortex flow being located at either 
(a)

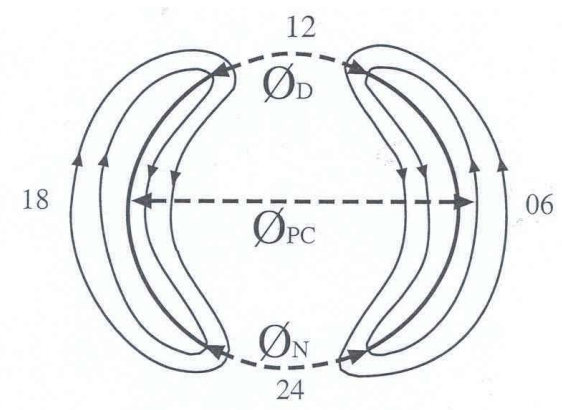

(b)

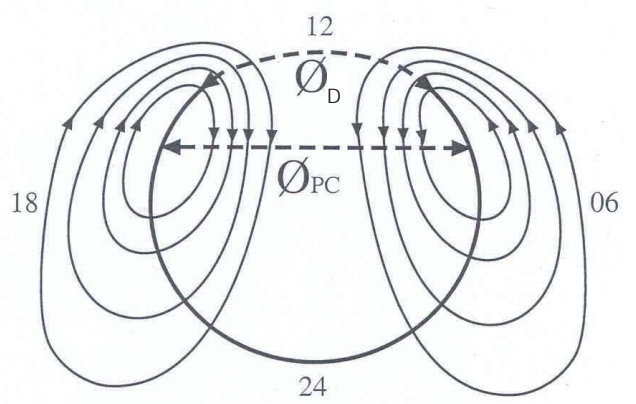

(c)

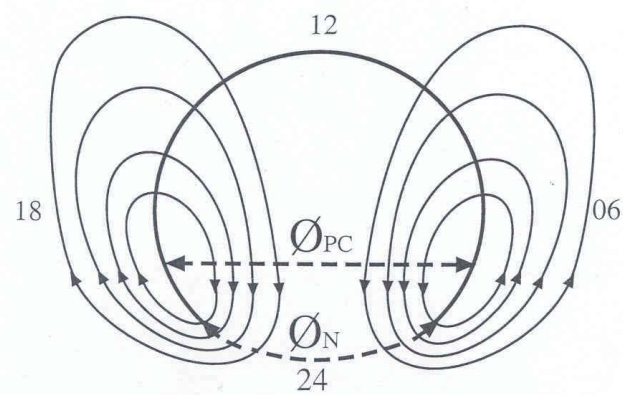

Fig. 1. (a) Ionospheric convection pattern resulting from balanced reconnection at the dayside magnetopause and in the tail. (b) Convection generated by purely dayside reconnection. (c) Convection generated by purely nightside reconnection (after Lockwood et al., 1990; Lockwood, 1991).

end of the dayside merging gap. Figure 1c shows the same for unbalanced nightside reconnection alone, as suggested by the expanding-contracting polar-cap (ECPC) model proposed by Siscoe and Huang (1985). Nightside reconnection results in the destruction of open flux, and the subsequent contraction of the polar cap. The flow during intervals dominated by nightside reconnection will be strongest on the nightside, with the foci of the twin-vortex located at either end of the nightside merging gap.

Magnetospheric substorms are characterised by the buildup and subsequent destruction of magnetic flux on the nightside of the Earth's magnetosphere. They are generally observed during, or just after, intervals of southward IMF. During the substorm growth phase, open flux produced by day- side reconnection is transported to the nightside by the solar wind, so that the magnetic flux in the tail lobes increases. This growth phase typically lasts 20 to $50 \mathrm{~min}$, before the tail becomes unstable and the substorm expansion phase is begun with rapid nightside reconnection occurring within the near-Earth plasma sheet (Cowley et al., 2002). The substorm expansion phase is characterised by a sudden brightening of the nightside aurora within the region called the "substorm auroral bulge". Within the substorm auroral bulge there exists large westward directed currents, driven by the very large conductivities created in the bulge ionosphere by the precipitating electrons. The electric field within this auroral bulge is found to be strongly suppressed (e.g. Morelli et al., 1995; Yeoman et al., 2000a,b; Khan et al., 2001; Cowley et al., 2002).

Even today we do not fully understand the mechanisms which trigger the onset of the substorm expansion phase, and controversy still surrounds how the high-latitude plasma flows are affected by magnetospheric substorms. Opgenoorth and Pellinen (1998) observed abrupt enhancements in ionospheric flows in response to substorm onset. They suggested that suppression of flow within the substorm current wedge (mapping essentially to the substorm auroral bulge) would result in an enhancement in the velocity of the ionospheric flows which were deflected around this region. However, such an enhancement of the deflected flow would not affect the overall transpolar voltage (Grocott et al., 2002). Grocott et al. (2002) using the SuperDARN HF radars have demonstrated the excitation of large-scale flow associated with the substorm expansion phase of a small high-latitude substorm. The excited flow pattern was of a twin-vortex form with foci located at either end of the subsorm auroral bulge. The transpolar voltage associated with the flow increased from $\sim 40 \mathrm{kV}$ prior to onset, to a peak of $\sim 80 \mathrm{kV}$ after $15 \mathrm{~min}$, decreasing to $\sim 35 \mathrm{kV}$ over $\sim 10 \mathrm{~min}$ in the substorm recovery phase.

There is at present a lack of knowledge concerning the average statistical flow patterns associated with different substorm phases, in contrast to the variety of statistical patterns of flow associated with different IMF orientations (e.g. Heppner and Maynard, 1987; Weimer 1995; Ruohoniemi and Greenwald, 1996). In this paper we aim to perform a statistical study investigating the high-latitude plasma flow in the interval $30 \mathrm{~min}$ before, until $30 \mathrm{~min}$ after substorm expansion phase onset. For this we use data from the Northern Hemisphere SuperDARN radars, the wide fields-of-view and an extensive number of these radars, making them excellent instruments for the investigation of spatial and temporal developments of global plasma flow. The substorm expansion phase onset is identified using optical measurements from the IMAGE FUV (far ultra-violet) imager. The IMAGE FUV instruments consists of several cameras. Here, the Wideband Imaging Camera (WIC) has been used to image the large scale aurora in the Northern Hemisphere. 
Northern Hemisphere SuperDARN radars

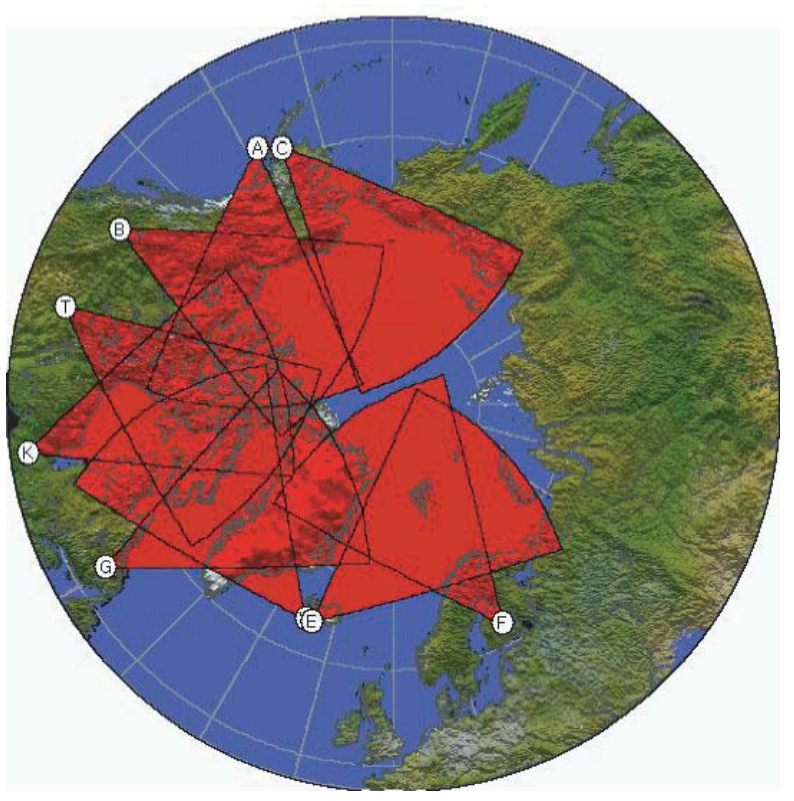

Fig. 2. The fields-of-view of the Northern Hemisphere SuperDARN radars.

\section{Instrumentation}

The ionospheric convection velocities presented in detail in this study are provided by the Northern Hemisphere SuperDARN radars, part of the international SuperDARN chain of HF radars (Greenwald et al., 1995). At present there are 9 SuperDARN radars imaging the high-latitude convection in the Northern Hemisphere, their fields-of-view are presented in Fig. 2. All the data presented in this statistical study were recorded in the year 2000 and the first half of 2001. The King Salmon radar (labelled C in Fig. 2) did not become operational until late 2001 and so no data from this radar have been included in this study. Each radar of the system is a frequency agile $(8-20 \mathrm{MHz})$ radar, routinely measuring the lineof-sight (1-o-s) Doppler velocity of echoes from ionospheric plasma irregularities. The radars each form 16 beams of azimuthal separation $3.24^{\circ}$. Each beam is gated into 75 range bins. In standard operation (normal resolution) mode each gate has a length of $45 \mathrm{~km}$ and the dwell time for each beam is $7 \mathrm{~s}$, giving a full 16 beam scan, covering $52^{\circ}$ in azimuth and over $3000 \mathrm{~km}$ in range (an area of over $4 \times 10^{6} \mathrm{~km}^{2}$ ), every 2 minutes.

The Imager for Magnetopause-to-Aurora Global Exploration (IMAGE) mission is dedicated to imaging the Earth's magnetosphere (Gibson et al., 2000). The Far Ultraviolet Camera Wideband Imaging Camera (WIC) provides global maps of the terrestrial aurora, in the spectral region from $140-190 \mathrm{~nm}$. The WIC is mounted on the rotating IMAGE spacecraft viewing radially outward and has a field-of-view of $17^{\circ}$ in the direction parallel to the spacecraft spin axis (Mende et al., 2000).

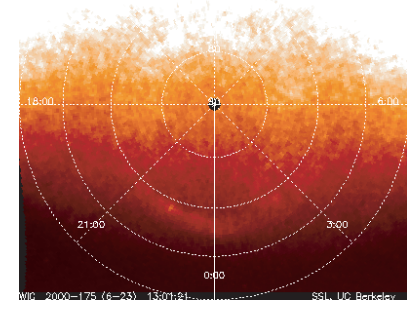

(c) 23 June 2000, 13:12 UT.

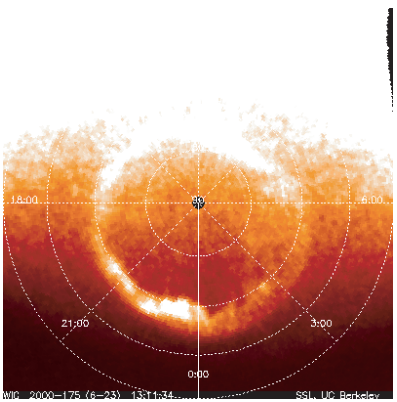

(d) 23 June 2000, 13:22 UT.

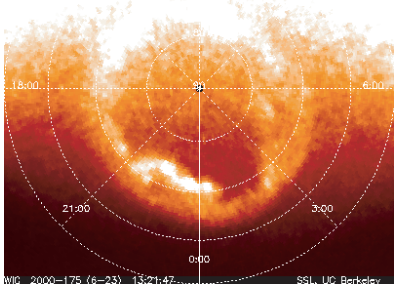

Fig. 3. Data from the Wideband Imaging Camera for the 23 June 2000. Figure 3a presents data from 13:01 UT, Fig. 3b presents data from 13:07 UT, Fig. 3c presents data from 13:12 UT and Fig. 3d presents data from 13:22 UT.

\section{The statistical analysis}

Mende et al. (2003) utilised the IMAGE FUV instrument to study the aurora in broad band using the WIC camera. They identified the onset time and the location (MLAT and MLT) of 113 substorms in 2000 and 2001, by a sudden brightening of the WIC images. Figure 3 presents WIC data from one of the substorm intervals identified by Mende et al. (2003), on 23 June 2000; this interval was included in the following statistical study. The figure presents data from 13:01 to 13:22 UT, where the auroral oval is clearly visible in all the plots. Substorm onset was identified at 13:07 UT. The plots clearly show an increase in auroral activity between 13:01 and 13:07 UT, with the signature of the onset of the substorm expansion phase.

One hundred and thirteen substorm intervals were identified from the IMAGE FUV, with all the intervals in the years 2000 or 2001 . During 67 of the intervals, the SuperDARN radars were running in normal-resolution common time mode (2-min resolution). For these 67 substorms we studied the l-o-s velocity measurements made by all the Northern Hemisphere SuperDARN radars, studying plasma flow from $30 \mathrm{~min}$ before substorm onset, until $30 \mathrm{~min}$ afterwards. We aimed to perform a spatial superposed-epoch analysis of plasma flows during the substorm growth and expansion phases. Initially, we mapped the 1-o-s velocities observed by all the Northern Hemisphere radars during each substorm interval into the global grid defined by the map- 
Gridded I-o-s velocity data, 23 June 2000, 13:06 UT (Northern hemisphere)

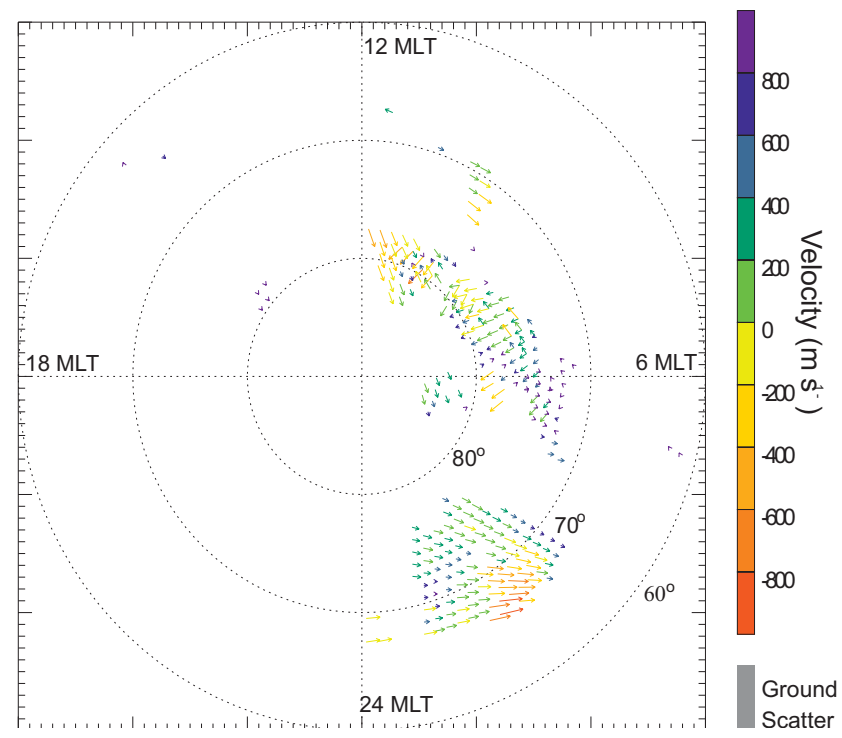

Fig. 4. Gridded line-of-sight velocity data from the SuperDARN radars for 23 June 2000 at 13:06 UT.

potential analysis technique (Ruohoniemi and Baker, 1998). This global grid has grid cells which are $1^{\circ}$ in lat $(\sim 111 \mathrm{~km}$ projected onto the Earth's surface), and as close to $111 \mathrm{~km}$ in longitude as possible. This gridding system has the advantage that it nearly equalizes cell areas, while the more conventional choice of a grid, defined by fixed steps in latitude and longitude, has the disadvantage of a severe latitudinal variation in cell area. Figure 4 presents an example of the gridded 1-o-s velocity data for one of the days included in the statistical study, on 23 June 2000, at 13:06 UT. The data are presented in a magnetic local time-magnetic latitude co-ordinate system in the Northern Hemisphere, with local midnight positioned at the bottom of each panel. During this interval there were data from all eight Northern Hemisphere SuperDARN radars available to us, except the Kodiak radar (radar A in Fig. 2).

Next, a substorm co-ordinate system was defined and each substorm interval was transformed in accordance with this co-ordinate system. The co-ordinate system defined points in terms of MLT and MLAT, where point $(0,0)$ was the MLT and MLAT of the substorm onset, determined from the IMAGE FUV data. For ease of data presentation the point $(0,0)$ is chosen to be at a MLAT of $65^{\circ}$ and a MLT of midnight in the following figures. This position was chosen since $71 \%$ of the substorm onsets identified in the FUV data occurred within $90 \mathrm{~min}$ of midnight, and the average latitude of substorm onset was $65^{\circ}$. We note that as $65^{\circ}$ is close to the equatorward edge of the SuperDARN field-of-view (in normal scan mode), the substorm-affected region may only be partially imaged by the radars.

The actual co-ordinate transformation is best explained by an example. For the first substorm interval, on 23 June 2000, the onset of the substorm expansion phase was identified at 13:07:17 UT, at a MLT of 23:00 and a MLAT of $69^{\circ}$. Our first step involved gridding all the 1-o-s velocity data for the period 12:37 to 13:37 UT, to the global grid described earlier. As the data has two-minute resolution, this represents 30 time samples. Next, for each of these 30 time samples, the locations of all vectors were rotated in local time in accordance with the substorm co-ordinate system, with both the origin and the end point of the vectors being rotated. Thus, a vector previously positioned at 23:00 MLT, would be repositioned at 24:00 MLT. This is described by the below formula:

$\varphi^{\prime}=\varphi+\alpha$

Where $\varphi$ is the original longitude of the vectors' start or end points, $\varphi^{\prime}$ is the new longitude of the flow vector and $\alpha$ is the angle of rotation. For this substorm $\alpha$ would be $15^{\circ}$, equal to the angle of rotation needed to rotate the position of substorm onset to local midnight.

Next, for all 30 time samples the entire convection pattern would be stretched so that all points at 69:00 MLAT would be moved to 65.0 MLAT. All other points would be stretched in latitude by a factor that increased linearly, with increasing latitudinal separation from $90^{\circ}$. This is defined by the formula below:

$\emptyset^{\prime}=\varnothing\left((90-65) /\left(90-\delta_{s}\right)\right)$

where $\varnothing$ is the co-latitude of the flow vector, $\varnothing^{\prime}$ is the transformed co-latitude of the vector, and $\delta_{s}$ is the latitude of substorm onset at substorm onset, equal to $69^{\circ}$ for the this substorm.

This method of stretching the convection pattern was devised as a method of creating a global substorm co-ordinate system that would most closely maintain the original shape of the polar cap. Hereafter, all latitudes and local times will be referred to in relation to this substorm co-ordinate system.

We transformed all 67 substorm intervals into the substorm co-ordinate system. We then combined the flow vectors from all of these substorms, considering each of the 30 time samples in turn. The 67 substorms together contained between 20000 and 30000 flow vectors at each of the 30 time samples. For each of the 30 time samples the 1-o-s velocities were combined using a cosine fitting technique to find the best-fit flow vector. Originally, we intended to perform the cosine fitting to the 1-o-s velocities at each grid point. However, we realised that this resulted in such a large number of vectors that it was difficult to present them visually. Instead, the cosine fitting technique was performed on all the 1-o-s velocities observed within an area that covered 1 grid point in latitude ( $1 \mathrm{deg}$ ), and 2 grid points in longitude (approx. $220 \mathrm{~km}$ ). Such cosine fitting was only performed if there was a minimum of five 1-o-s velocity measurements within this area. Figure 5 presents an example of this cosine fitting technique, presenting the angle and velocity of the 1o-s velocities observed in the area extending from $70^{\circ}$ to $71^{\circ}$ in latitude and from $0^{\circ}$ to $6^{\circ}$ in longitude, $30 \mathrm{~min}$ before substorm onset. Overplotted is a dashed line showing the 1-o-s 


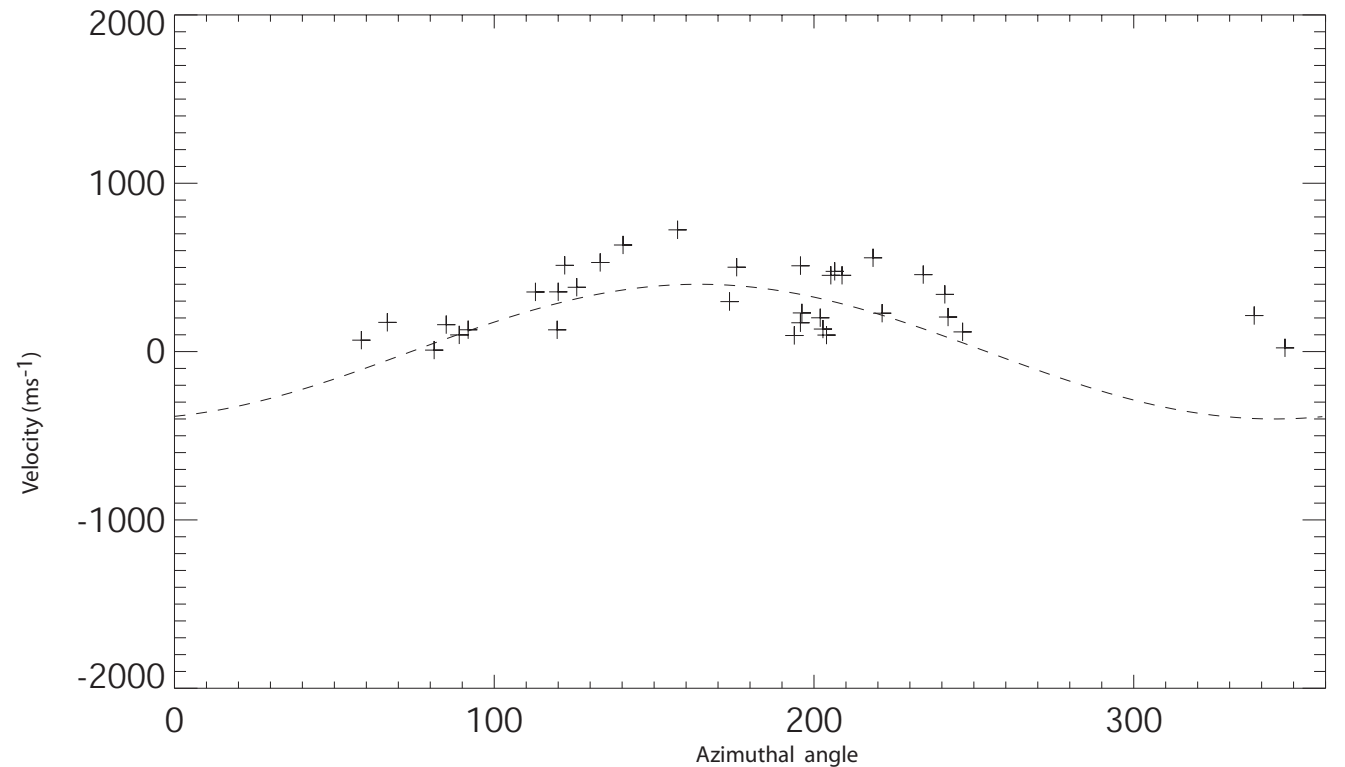

Fig. 5. The velocity magnitude and azimuthal angle of l-o-s velocities observed by all the 67 substorms between $70^{\circ}$ and $71^{\circ}$ latitude and $0^{\circ}$ and $6^{\circ}$ longitude at $30 \mathrm{~min}$ before substorm onset. The overplotted dashed line shows the cosine variation of the best-fit velocity.

velocity versus 1-o-s angle for the best-fit flow vector. The velocity was calculated according to the formula below:

$V=V_{\text {best }} \cos \left(\alpha-\alpha_{\text {best }}\right)$,

where $V_{\text {best }}$ is the velocity of the best-fit flow, $\alpha_{\text {best }}$ is the angle of the best-fit flow, $\mathrm{V}$ is the 1-o-s velocity component and $\alpha$ is the magnetic azimuthal angle.

The end result is 30 convection maps of best-fit flow vectors representing the Northern Hemisphere global convection pattern every two minutes from $30 \mathrm{~min}$ before substorm onset until $30 \mathrm{~min}$ afterwards. These maps were used as a basis to perform a detailed statistical study of high-latitude convection during the substorm growth and expansion phases. We were also able to determine estimates of cross polar-cap potential.

\section{Results}

\subsection{IMF conditions}

Before discussing the flows we present the upstream IMF conditions for the substorm intervals, from the ACE spacecraft, to demonstrate the average background conditions. For each interval we calculated a delay between the time of the solar wind observation at ACE and the time it impinged at the dayside magnetopause, using the algorithm of Lester et al. (1993). The average IMF conditions (GSM) for all 67 substorm intervals are presented in Fig. 6. The plot shows that, on average the IMF $B_{x}$ component is slightly positive, while the average IMF $B_{y}$ and $B_{z}$ components are negative. From five minutes before substorm onset until onset itself the magnitude of the IMF $B_{z}$ component decreases (becomes less negative), increasing by $\sim 1.5 \mathrm{nT}$.

\subsection{Flow vectors}

Figure 7 presents the cosine-fitted vectors at 10-min steps from $30 \mathrm{~min}$ prior to substorm onset (Fig. 7a) until substorm onset (Fig. 7d). Each plot includes data for a two-minute sample (the resolution of the radar data). The vectors are presented in what we term the substorm MLT/MLAT coordinate system described earlier, where the onset location is marked by a black cross on the plot. The velocity magnitude is represented both by the length of the vector and by its colour, with blue representing the strongest flow and yellow the weakest. In Fig. 7a the flow presented is a two-cell convection pattern, with plasma flowing away from the Sun and across the polar cap at higher latitudes and returning at lower latitudes. Flows out of the polar cap on the nightside appear relatively weak. There is an asymmetry in the strength of the low-latitude sunward return flow, with stronger flows observed in the pre-midnight time sector compared to the postmidnight sector.

Figure $7 \mathrm{~b}$ presents the cosine-fitted vectors $20 \mathrm{~min}$ before substorm onset. The high-latitude plasma flow into the polar cap on the dayside has now become stronger and more structured. There is still a dawn-dusk asymmetry in the strength of the sunward flow at lower latitude. The flows across the polar cap are also stronger than 10 min previously. Figure $7 \mathrm{c}$ presents the flow vectors $10 \mathrm{~min}$ before substorm onset. Strong flows into the polar cap are now observed between $\sim 08: 00$ and $\sim 14: 00$ MLT. Compared to the flow vectors observed $30 \mathrm{~min}$ before substorm onset, the equatorward boundary of radar backscatter at midnight has moved from a latitude of $61^{\circ}$ to $59^{\circ}$, the poleward boundary of midnight backscatter has also moved equatorward to a latitude of $82^{\circ}$, from $84^{\circ} 30 \mathrm{~min}$ before onset. 


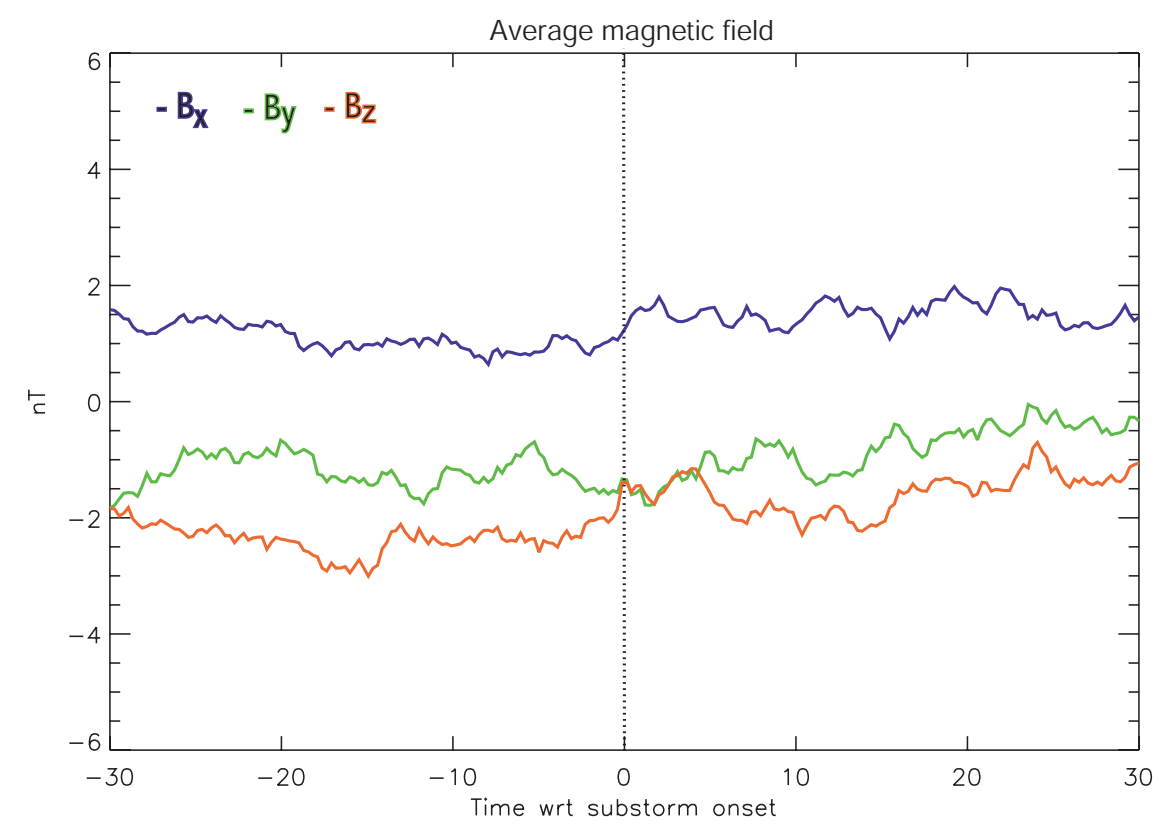

Fig. 6. Average IMF conditions for all substorms. The IMF $B_{x}$ component is coloured blue, the $B_{y}$ component is green and the $B_{z}$ component is red.

Figure $7 \mathrm{~d}$ presents the flow vectors at substorm onset. At the dayside the magnitude of the flow into the polar cap appears to have decreased compared to the flow observed 10 min before substorm onset, while the magnitude of the high-latitude plasma flowing out of the polar cap at the nightside has increased. There is an asymmetry in the strength of the nightside high-latitude plasma flowing out of the polar cap, with stronger flows observed in the pre-midnight region compared to the post-midnight region. The strength of the low-latitude return flow observed between $\sim 19: 00$ and $\sim 21: 00$ MLT has increased considerably. Between the MLTs of 21:00 and 24:00 we observe high velocity plasma flows out of the polar cap, travelling to lower latitudes. At a latitude of $\sim 70^{\circ}$ between 22:30 and 24:00 MLT, these fast flows appear to be stalled and diverted, travelling to lower latitudes at MLTs earlier than 22:30 and later than 24:00. Thus, there is evidence of a suppressed flow region on the nightside, covering an area from approx $62^{\circ}$ to $70^{\circ}$ latitude and from 22:30 to 24:00 MLT, with fast flows diverted round its edges.

Figure 8 presents the flow vectors 4 min after substorm onset until 28 minutes after substorm onset. In Fig. 8a there are strong high-latitude flows out of the polar cap on the nightside. The nightside suppressed flow region observed at substorm onset is now more clearly defined, with enhanced plasma flow now being diverted to latitudes of $59^{\circ}$ to $62^{\circ}$, which is below this region of suppressed flow. There appears to be stronger anti-sunward flows in the high-latitude dusk region as compared with the dawn region. The strong low-latitude return flow pre-midnight of the auroral onset region continues, with particularly strong flows observed in the post-dusk sector. Figure $8 \mathrm{~b}$ presents the flow vectors $14 \mathrm{~min}$ after substorm onset. The flow pattern is very similar to the flow pattern observed $4 \mathrm{~min}$ after substorm onset. The suppressed flow region is still clearly observable, although the strong flows at lower latitudes are somewhat reduced. In order to guide the eye, a dotted black circle marks the approximate position of this region. Figure $8 \mathrm{c}$ presents the flow vectors observed $20 \mathrm{~min}$ after substorm onset. There is still strong plasma flow leaving the polar cap on the nightside, although this flow appears much less structured than the flow observed $14 \mathrm{~min}$ after the substorm onset. The nightside suppressed flow region appears to be further extended, stretching from approx. $60^{\circ}$ to $70^{\circ}$ MLAT, and from $\sim 22: 00$ to 02:30 MLT, with enhanced plasma flow being diverted around this region.

Figure 8d presents the flow vectors observed 28 min after substorm onset. The ionospheric flows are now much less structured than the flows observed 20 min after substorm onset, but there is still strong plasma flow directed both into and out of the polar cap.

\subsection{Backscatter occurrence}

Figure 9 presents radar backscatter occurrence during the substorm growth phase, from $30 \mathrm{~min}$ before substorm onset (Fig. 9a) until substorm onset (Fig 9d), at intervals of $10 \mathrm{~min}$. The plots shows how many Doppler velocity measurements have been used in the cosine fit to derive each vector in the flow plots. The occurrence is colour coded with blue representing the maximum number of points in the grid cell, and yellow the minimum. White represents less than 5 data points in the grid cell (note that the cosine fit is only performed if there is a minimum of 5 data points in a grid cell).

During the growth phase there is little change in the occurrence of radar backscatter. The greatest concentration of 


\section{Northern hemisphere plasma flow vectors}
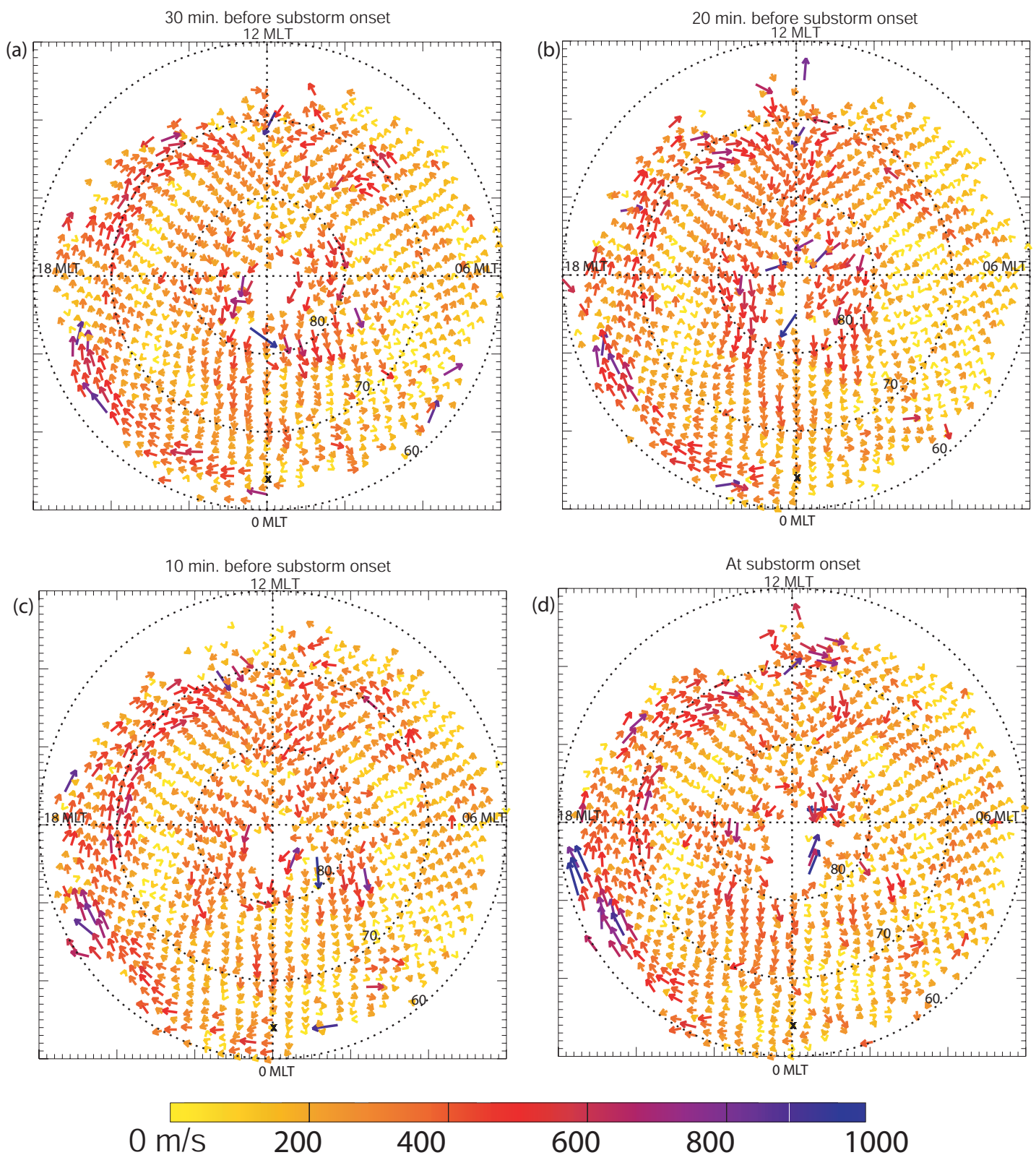

Fig. 7. Cosine-fitted velocity flow vectors at 10-min steps from 30 min prior to substorm onset (Fig. 7a) until substorm onset (Fig. 7d). The velocity magnitude is represented both by the length of the vector and by its colour, with blue representing the strongest flow and yellow the weakest.

radar backscatter is centred at the dayside. There is a slight dawn/dusk asymmetry in the occurrence of data points between the latitude of $65^{\circ}$ to $80^{\circ}$, with more points being observed in the dusk region as compared to the dawn region. Figure $9 \mathrm{~d}$ presents the radar backscatter at substorm onset. Nightside backscatter has moved equatorward. There is a clear change in the occurrence plots compared to the growth phase, with a decline in the amount of backscatter in the midnight region, although the occurrence of backscatter in the midday region remains the same.
Figure 10 presents the occurrence of radar backscatter during the substorm expansion phase, from four minutes after substorm expansion phase onset (Fig. 10a) until $28 \mathrm{~min}$ after substorm expansion phase onset (Fig. 10d). In Fig. 10a the greatest concentration of backscatter occurrence is clearly skewed to the post-noon sector, observed at magnetic latitude of approx. $64^{\circ}$ to $70^{\circ}$ and MLT of 12:00 to 16:00. This asymmetry of radar backscatter can be observed during the entire expansion phase. As the expansion phase develops there is a decreasing amount of nightside backscatter, eventually af- 


\section{Northern hemisphere plasma flow vectors}
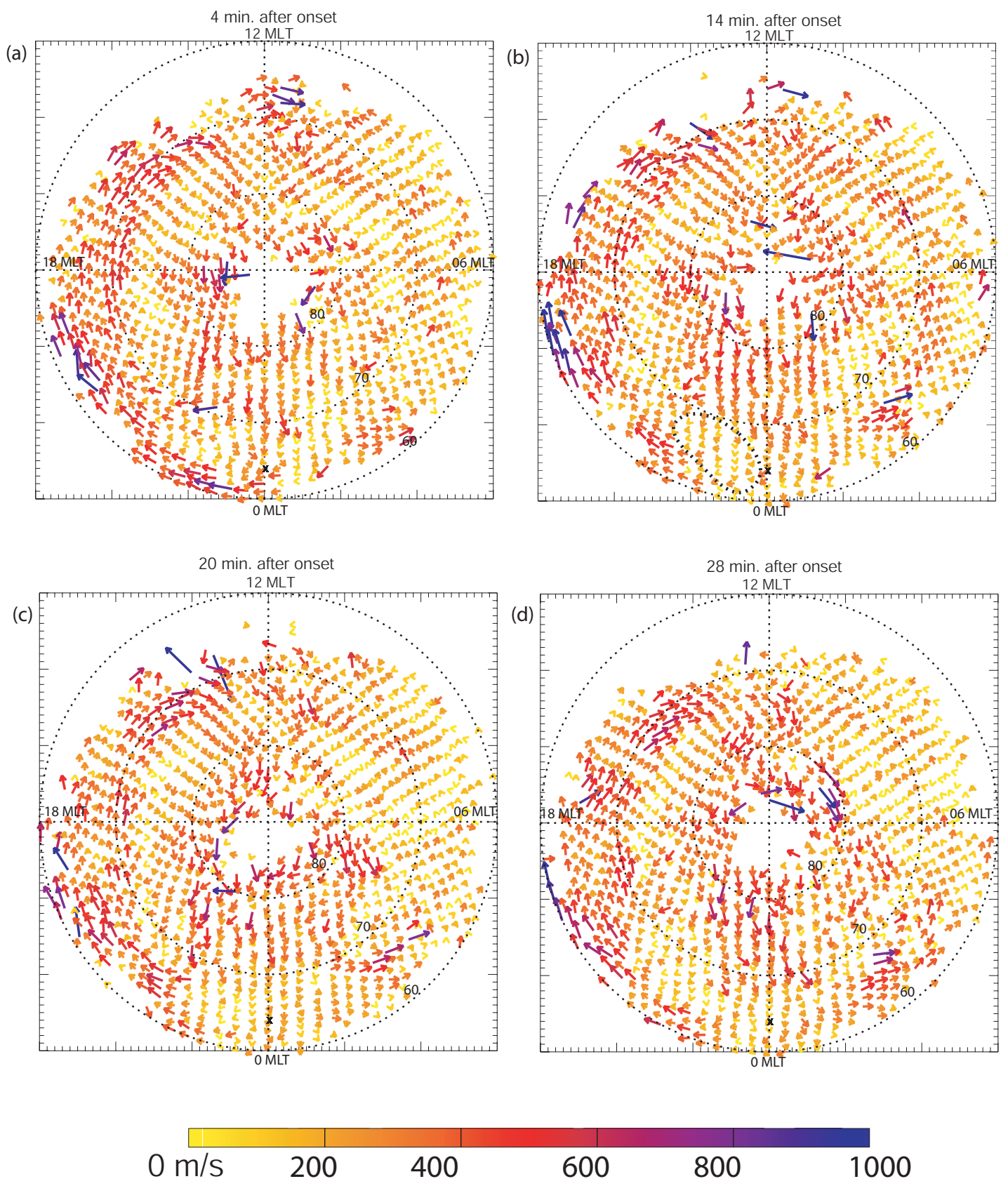

Fig. 8. Cosine-fitted velocity flow vectors presented from 4 min after substorm onset (Fig. 8a) until 28 min after substorm onset (Fig. 8 d). The velocity magnitude is represented both by the length of the vector and by its colour, with blue representing the strongest flow and yellow the weakest. In Fig. 8b a dotted black circle marks the approximate position of the suppressed flow region.

fecting almost the entire nightside region from dusk to dawn. However, the occurrence of radar backscatter in the dayside region only shows a small decline.

\subsection{Polar cap velocities}

The cosine-fitted vectors were used to derive the mean velocities across the entire polar cap, and across the dawn and dusk sectors of the polar cap. The flow reversal boundary was considered a proxy for the polar cap boundary. The first step was to measure the width of the polar cap across the dawndusk meridian, measured from the position of flow reversal in the dawn sector to the position of flow reversal in the dusk sector. This measurement was taken as a proxy for the width of the polar cap. We then calculated the mean anti-sunward velocity across the dawn-dusk meridian, and also separately 

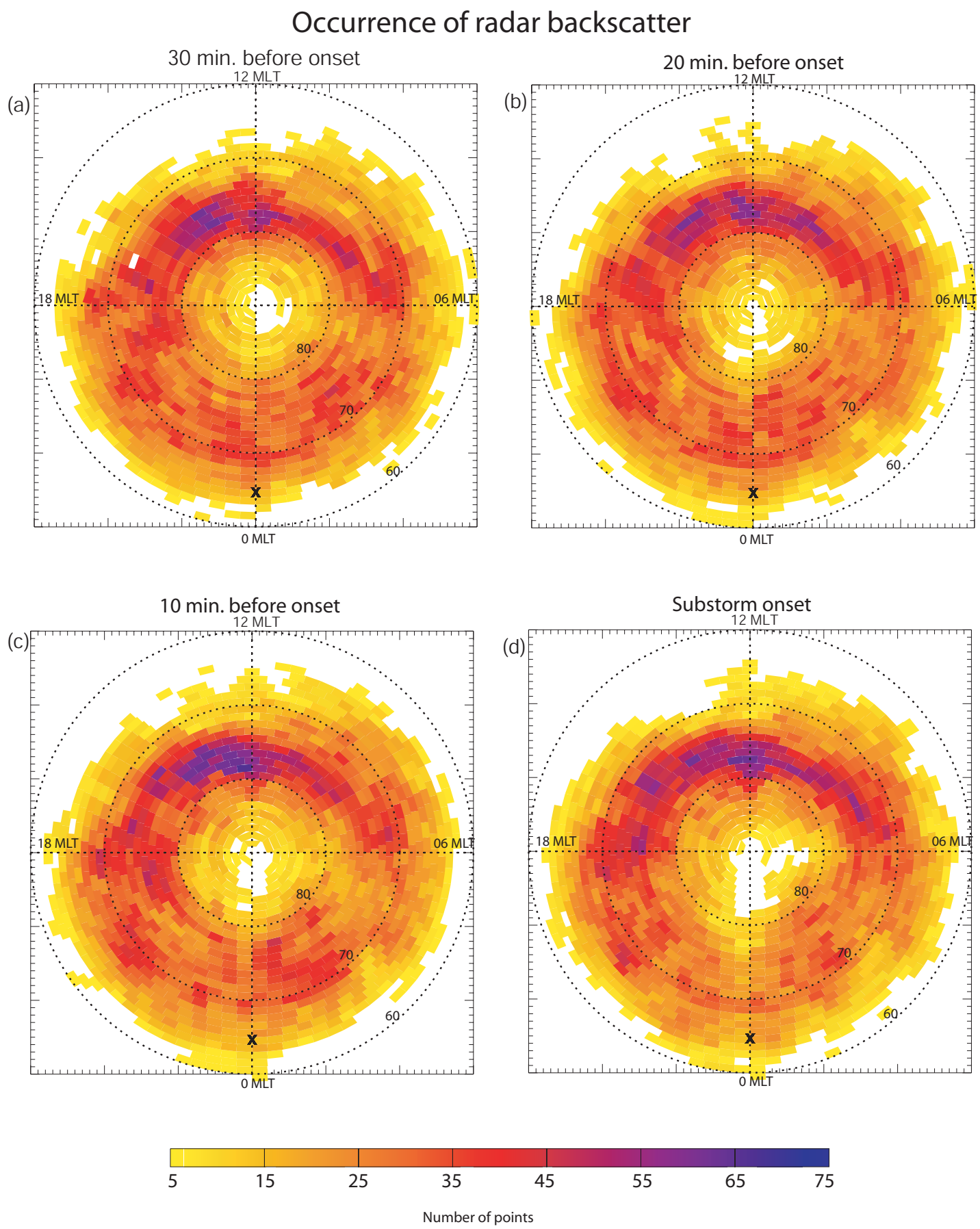

Fig. 9. Radar backscatter occurrence from $30 \mathrm{~min}$ before substorm onset (Fig. 9a) until substorm onset (Fig. 9d). The occurrence is colour coded with blue representing the maximum number of points and yellow the minimum. White represents less than 5 data points.

across the dawn and dusk regions. This velocity was derived by averaging all cosine-fitted vectors along the dawn-dusk meridian for each time sector. As each cosine-fitted vector is derived from a number of vectors itself, the mean velocity was weighted by the number of 1-o-s velocities used to estimate each cosine-fitted vector. So, for the example presented in Fig. 5, this cosine-fitted velocity would have a weight of 34. Figure 11 presents the anti-sunward component of the average flow velocity across the dawn (blue line) and dusk (red line) sectors of the polar cap and across the entire polar cap (black line). Each velocity has an error bar associated with it, which is the standard error of the weighted mean. At each time sample we performed a student t-test in order to investigate whether the difference in the weighted mean between the dawn and the dusk sectors was significant at the 95\% confidence level. If the difference in velocity was significant, the dawn and dusk velocities were marked with a cross. There are only 9 time samples, out of the 30, that 


\section{Occurrence of radar backscatter}
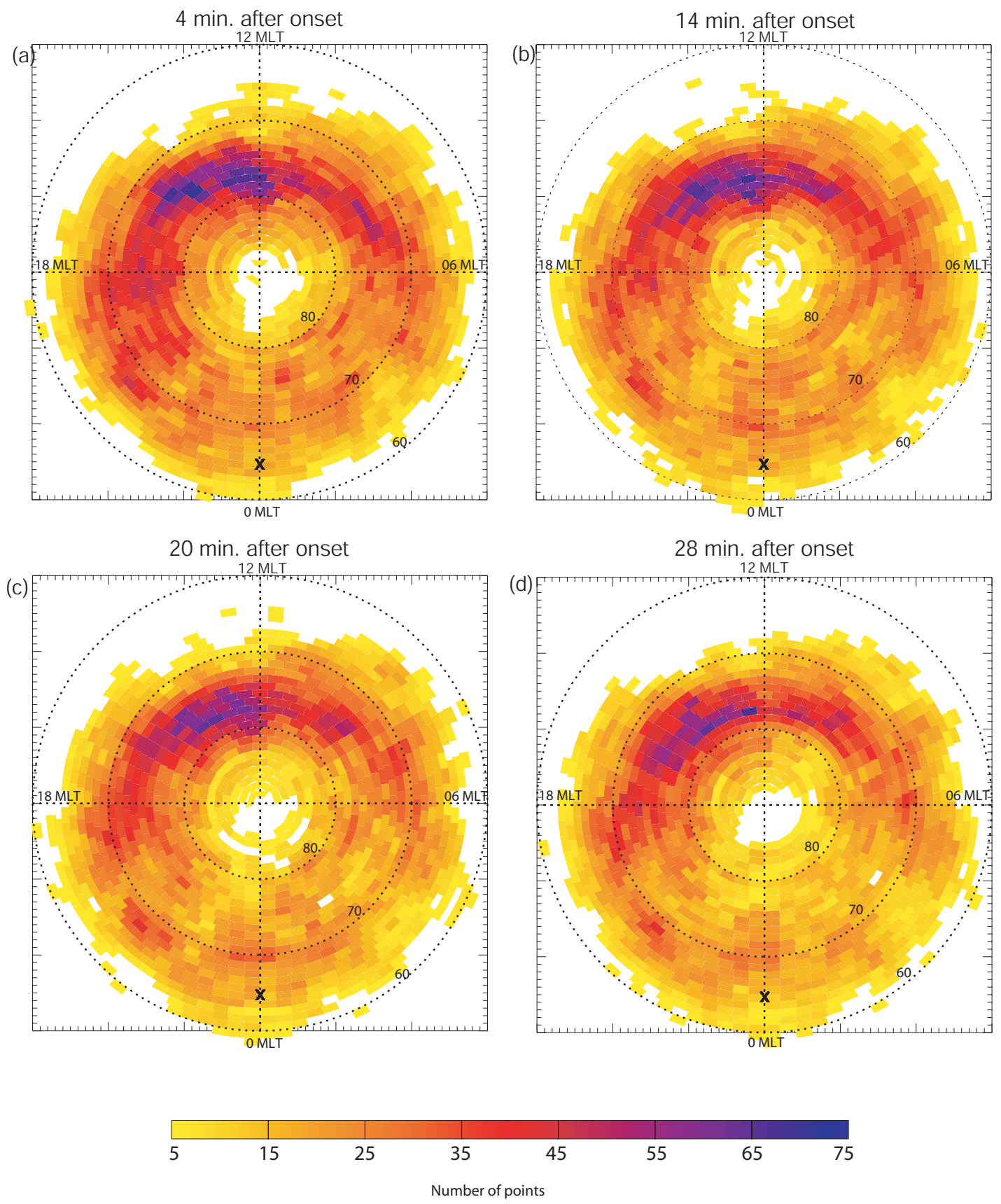

Fig. 10. Radar backscatter occurrence from four minutes after substorm expansion phase (Fig. 10a) until 28 min after substorm expansion phase (Fig. 10d). The occurrence is colour coded with blue representing the maximum number of points and yellow the minimum. White represents the less than 5 data points.

the difference between the dawn and dusk velocities was significant at the $95 \%$ confidence level; at each of these times the dusk velocity was significantly larger than the dawn velocity, supporting the observational evidence from the plots presented in Figs. 7 and 8 that the flows in the high-latitude dusk sector are typically larger than in the dawn sector.

The polar-cap velocity in both the dawn and dusk sectors fluctuated rapidly during the time interval studied here. Dur- ing the growth-phase the total polar-cap velocity reaches a minimum 14 min before substorm onset. The polar-cap velocity reaches a maximum 12-14 min after substorm onset, after which the velocity starts to decrease, before increasing again 22 min after onset. 


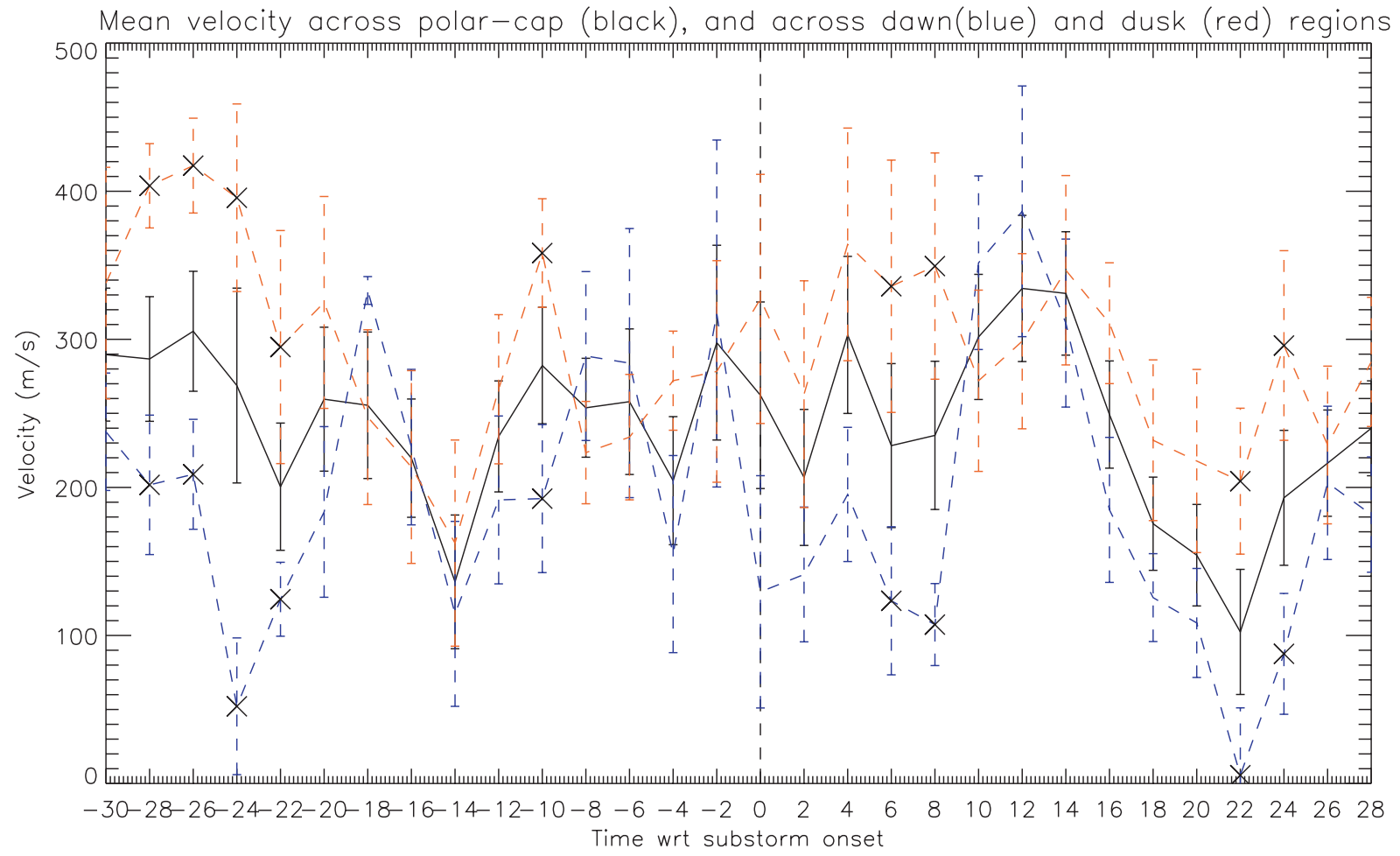

Fig. 11. The anti-sunward component of the weighted mean flow velocity across the polar cap (black line) and across the dawn (blue line) and dusk (red line) regions. The error bars are the standard error at each point.

Dawn-to-dusk cross polar-cap potential

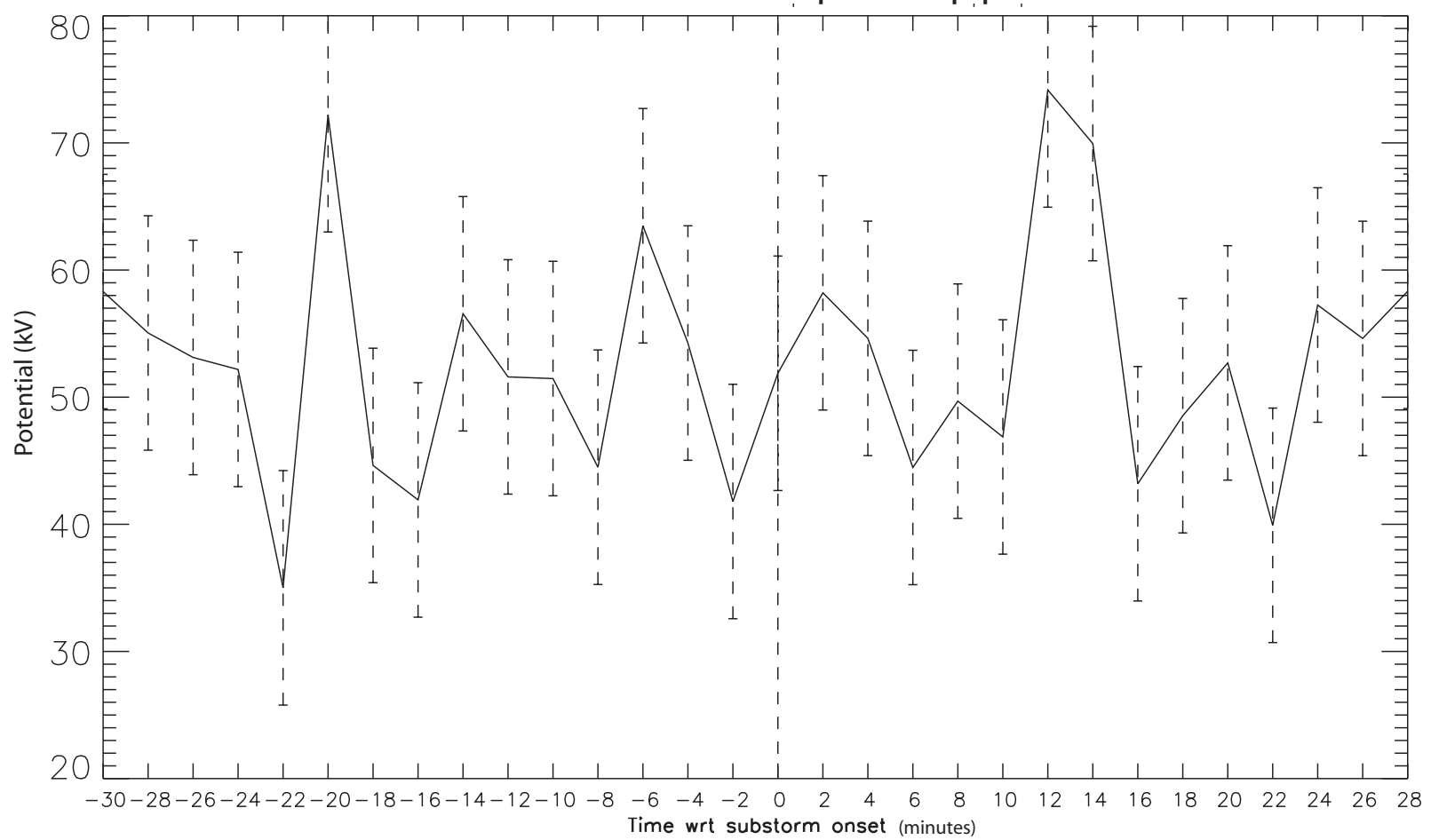

Fig. 12. The dawn-to-dusk cross polar-cap potential. The error bars represent the standard deviation of the polar-cap potential. 


\subsection{Determining the cross polar-cap potentia}

The dawn-to-dusk cross polar-cap potential $(\Phi \mathrm{pc})$ is described by:

$\Phi p c=\int V_{\perp} B d l$,

where $V_{\perp}$ is the anti-sunward component of the plasma flow at a given point along the dawn-dusk meridian, $d l$ is the width along the dawn-dusk meridian over which the measurement is made and $B$ is the polar magnetic field.

As in Sect. 4.4 the dawn-to-dusk flow reversal boundary is taken as a proxy for the polar cap boundary. For each time sample the anti-sunward component of the cosinefitted velocity at each grid point is multiplied by the length of the dawn-to-dusk polar boundary along which it is observed. This is done all the way along the polar cap boundary and the individual potentials are then summed to create the cross polar-cap potential. Figure 12 presents the cross polar cap potential, from $30 \mathrm{~min}$ before substorm onset until $30 \mathrm{~min}$ after. The cross polar cap potential is not an absolute value, as no attempt has been made to compensate for the stretching/shrinking of the convection pattern performed when transforming the substorm convection patterns into the substorm co-ordinate system. However, as each substorm was stretched by the same amount over the entire time interval of the substorm, the value of the cross polar cap potential presented represents the relative change of the cross polarcap potential during the substorm. The average cross polarcap potential is $53 \pm 9 \mathrm{kV}$. The error bars presented on the graph is the standard deviation of the cross polar-cap potential. Although there are rather large fluctuations in the dawnto-dusk potential, some general trends can be observed. During the substorm growth phase the dawn-to-dusk transpolar voltage is at a maximum of $72 \mathrm{kV} 20 \mathrm{~min}$ before substorm onset. Just before substorm onset the transpolar voltage is $\sim 40 \mathrm{kV}$. The voltage reaches a maximum of $74 \mathrm{kV} 12 \mathrm{~min}$ after onset.

\subsection{Low-latitude velocity and potential}

We determined the weighted mean of low-latitude return flow from the equatorward edge of the polar-cap boundary to the equatorward limit of the radar field-of-view across the dawn and dusk sectors, using the same method used to derive the mean high-latitude velocities described in Sect. 4.4. The mean was weighted by the number of points used to derive the cosine-fitted velocities. The velocities are presented in Fig. 13. Points that are different at a $95 \%$ confidence level are marked by an " $x$ ". At almost all times the dusk velocity is significantly larger than the dawn velocity.

We calculated the low-latitude potential from the equatorward edge of the polar cap boundary and to the edge of the convection pattern. This potential was calculated in the same way as we calculated the cross polar cap potential in Sect. 4.5. The results are presented in Fig. 14. The average low-latitude potential is $36 \pm 7 \mathrm{kV}$, with the standard deviation presented as error bars in Fig. 14. The average low-latitude potential is much smaller than the average cross polar-cap potential. We would expect the two to be the same. We believe that this discrepancy is probably due to the edge of the convection pattern being equatorward of the equatorward edge of the SuperDARN field-of-view, causing the apparent saturation of the low-latitude potential at around $40-50 \mathrm{kV}$. There is a large difference in the low-latitude potentials observed in the dawn and dusk sectors, with the potentials observed in the dusk sector considerably larger than the potential observed in the dawn sector. This is due to the much larger velocities observed at low-latitude in the dusk sector as compared with the dawn sector. The velocities presented in Fig. 11 show that there is a general trend toward larger velocities in the dusk sector than in the dawn sector also at higher latitude, although this difference is much more pronounced at lower latitudes.

\section{Discussion}

In this study we have performed a statistical superposed epoch analysis of the flow during the growth and expansion phases of magnetospheric substorms, analysing the plasma flow from $30 \mathrm{~min}$ before substorm onset until $30 \mathrm{~min}$ after substorm onset for 67 substorms. No attempt has been made to identify the onset of the substorm recovery phase, although as the typical length of the substorm expansion phase is of the order of 30 to $60 \mathrm{~min}$ (Lui, 1991), we can assume that the majority of the substorms will not have progressed into the recovery phase during the intervals selected for this study.

Global grids of the cosine-fitted flow vectors are presented. During the substorm growth phase, strong flow was observed flowing into the polar cap on the dayside, and as the growth phase progressed, the strengths of these flow increased, such that they could be observed over a wider range of local times. As early as $20 \mathrm{~min}$ before substorm onset dayside plasma flows in the midday region were observed to become more structured and directed more towards the polar cap. During the growth phase the dawn-to-dusk transpolar voltage peaked 20 min before substorm onset, illustrating increased plasma flux flowing across the polar cap. The anti-sunward component of the plasma velocity flowing across the dawn sector of the polar cap peaked $18 \mathrm{~min}$ before onset. As the growth phase progressed, the equatorward and poleward boundaries of the nightside radar backscatter moved to lower latitudes.

The equatorward motion of HF backscatter during the substorm growth phase has been reported by Lewis et al. (1997), and has since been observed by a number of authors (e.g. Yeoman et al., 1999, 2000a; Provan et al., 2002; Milan et al., 2003). Such systematic equatorward motion of radar backscatter is believed to correspond to an equatorward motion of the structured precipitation of the expanding auroral oval. This expansion is a result of unbalanced dayside reconnection adding open flux to the polar cap during the growth phase, causing the poleward and equatorward edges of the polar cap to move to lower latitudes (McPherron, 1970). 


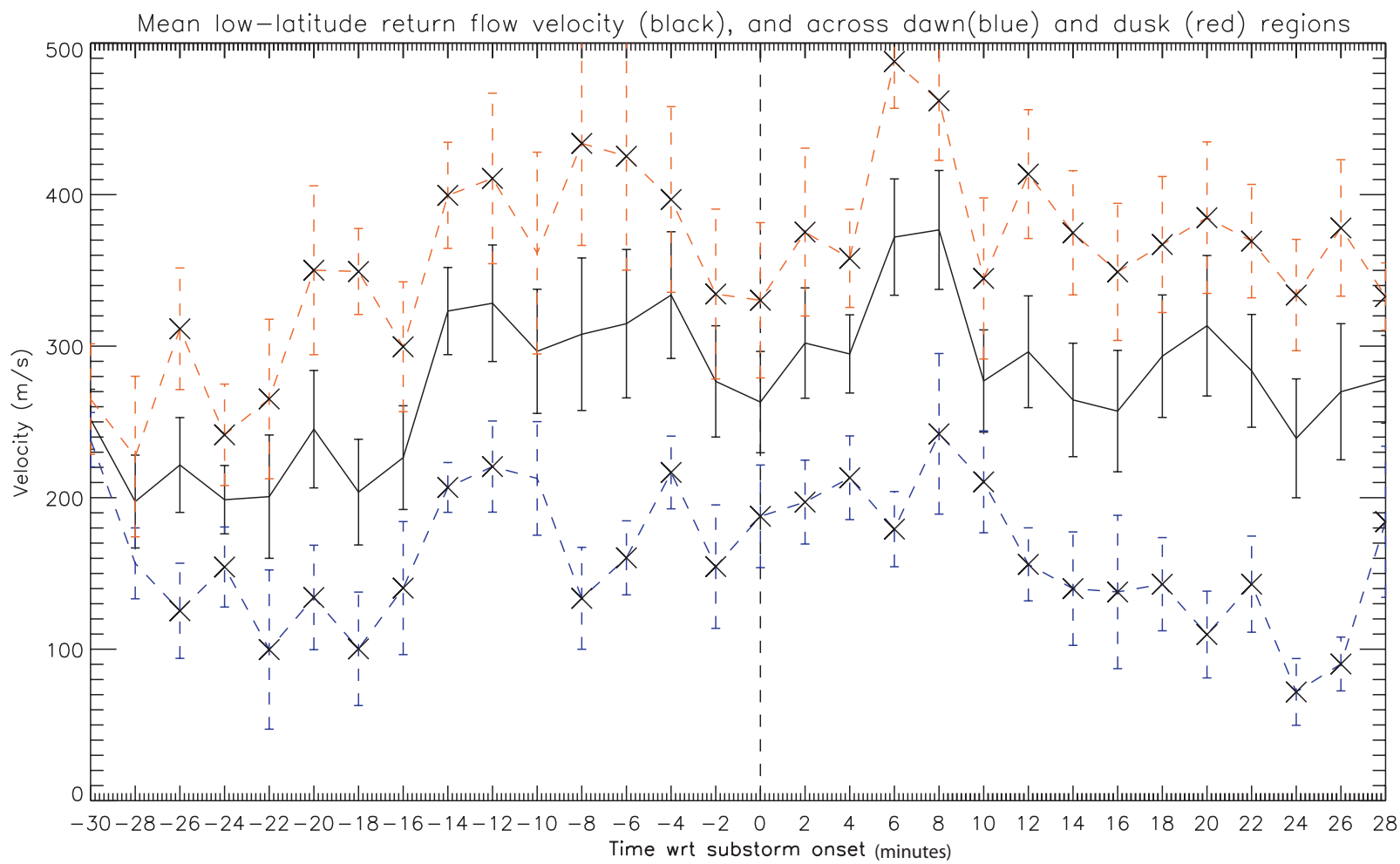

Fig. 13. The anti-sunward component of the weighted mean flow velocity across the low-latitude return flow region (black line) and across the dawn (blue line) and dusk (red line) sectors. The error bars are the standard error at each point.

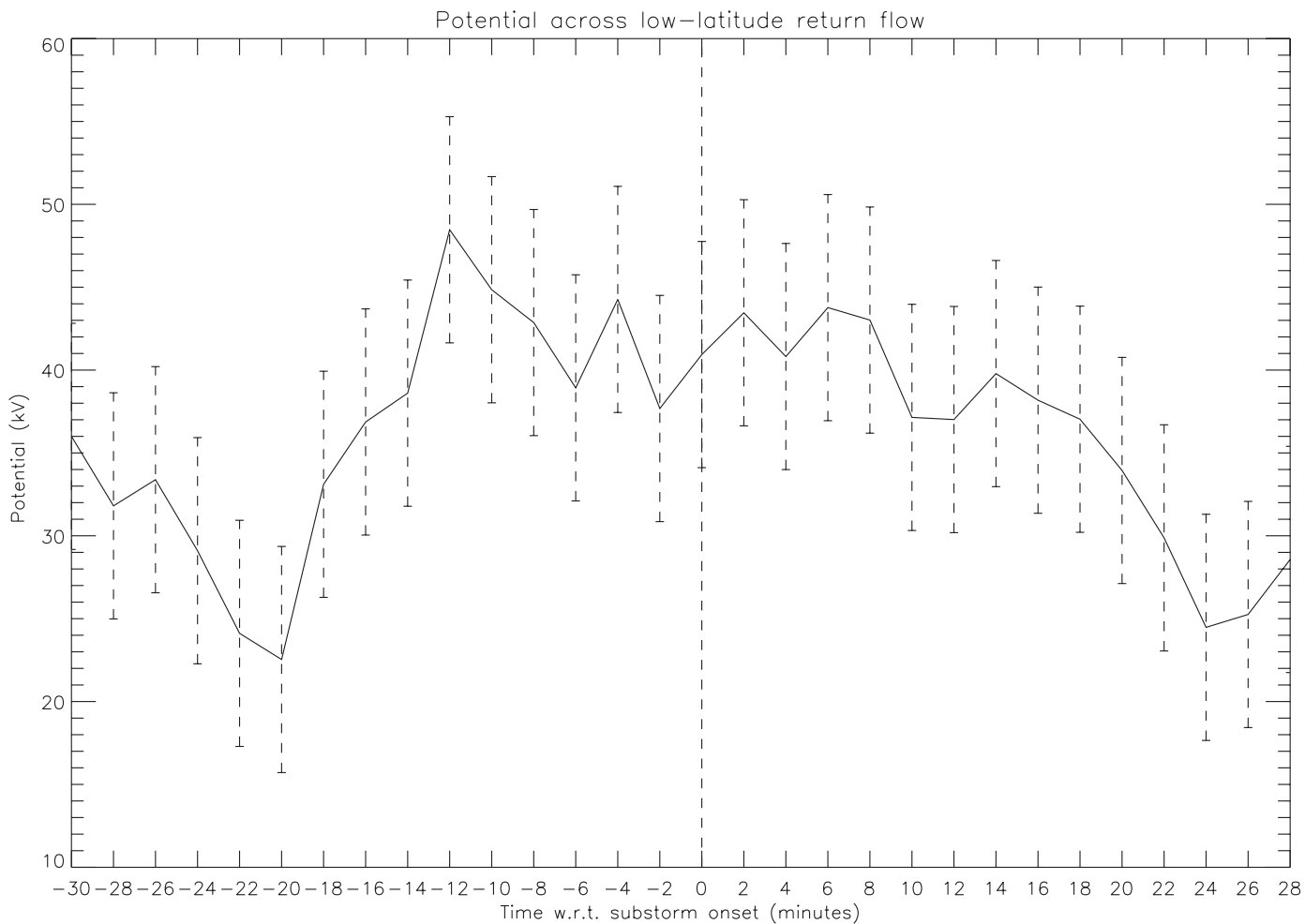

Fig. 14. The average potential across the low-latitude return flow region. The error bars represent the standard deviation of the potential. 
Following substorm onset there is a reduction of nightside radar backscatter. As the expansion phase evolves so too does this depletion in nightside backscatter. Many studies have reported a lack of nightside HF radar data following expansion phase onset, due to the absorption of radio waves in the ionosphere (e.g. Lewis et al; 1997, Yeoman and Lühr, 1997; Lester, 2000) by the precipitating auroral electrons. Our statistical study demonstrates that this depletion in nightside backscatter occurs almost immediately following substorm onset, and that it further develops during the substorm expansion phase, eventually affecting a sizeable part of the nightside ionosphere. Previous studies by, for example, Milan et al., 1996 and Milan et al., 1999, have discussed the disruption of HF propagation during substorm onset.

During the expansion phase a region of suppressed flow is observed, initially covering a region from $22: 30$ to 24:00 MLT, and from $\sim 62^{\circ}$ to $\sim 70^{\circ}$ MLT. Fast flows appear to be deflected around this suppressed flow region, in such a manner that the basic two-cell convection pattern was preserved. Previous workers have also observed regions of nightside flow suppression when studying the ionospheric response to a substorm expansion phase, for example, Yeoman et al. (2000a), Fox et al. (2001), Khan et al. (2001) and Grocott et al. (2002). It is likely that this suppressed flow region is related to the increased auroral and magnetic activity previously reported during the substorm expansion phase. For example, Khan et al., 2001, presented case studies of two complete "classic" substorm cycles where enhanced auroral brightening and increased magnetic activity was reported to be observed over a similar MLT/MLAT range and on a similar time scale as the suppressed flow region reported here. They also reported that ionospheric flows within the substorm auroral bulge became semi-stagnant throughout the expansion phase. The surrounding flow generally remained vigorous and deflected around the semi-stagnant region. They believed such flow stagnation to be due to the high electrical conductivity of the bulge ionosphere compared with the surrounding region.

Opgenoorth and Pellinen (1998) observed an abrupt enhancement in ionospheric flows in response to substorm onset. They suggested that extreme dipolarisation of a magnetospheric segment inside the substorm current wedge would result in a suppression of flow in this region, and the deflection and relative enhancement of the flow around this region. However, this deflection and resultant flow enhancement would not change the overall transpolar voltage. In Fig. 12 we present the dawn-to-dusk cross polar-cap potential. The transpolar voltage is $\sim 40 \mathrm{kV}$ just before substorm onset and increases to $74 \mathrm{kV} 12 \mathrm{~min}$ after onset. This is despite the average IMF $B_{z}$ component becoming increasingly less negative from $\sim 5 \mathrm{~min}$ before substorm onset until $\sim 4$ min after substorm onset. Such enhancement in the total transpolar flux associated with substorm onset was previously observed by Grocott et al. (2002) while studying an isolated substorms. The transpolar voltages derived by Grocott and co-workers (2002) are very similar to the voltage magnitudes presented here. Our detailed statistical study clearly proves that nightside reconnection during substorm onset results in enhanced flux being driven across the polar cap.

In order to quantify the strength of the plasma flow across the polar-cap, and within the return flow, we presented the mean anti-sunward flow component across the polarcap (Fig. 11) and across the low-latitude return flow region (Fig. 13). Figure 11 demonstrates that during the substorm growth phase the flow across the polar-cap is at a minimum $14 \mathrm{~min}$ before substorm onset, reaching a maximum $12 \mathrm{~min}$ after substorm. Figure 13 demonstrates that the magnitude of the return flow starts to increase at substorm onset and continues until $8 \mathrm{~min}$ after substorm onset. Using the Student's t-test we found that the variation in the return flow velocity observed at these two times was significant at the $95 \%$ confidence level. Flow excitation during larger substorms has also previously been reported by Sandholt et al. (2002).

It is thus clear that nightside reconnection occurring during the substorm expansion phase resulted in the excitation of new voltage and large-scale flow within the polar cap. This has previously been suggested by Lockwood et al. (1990) and Cowley and Lockwood (1992), although, to our knowledge, the results presented here are the first to prove this on a statistical basis. We are not stating that the increase in plasma flow around the nightside suppressed flow region cannot also excite plasma flow, but the large increase in the transpolar voltage during the expansion phase onset would suggest that the main driver behind the excitation of large-scale plasma flow is nightside reconnection.

Studying the dawn-to-dusk transpolar voltage (Fig. 12) illustrates that between $6 \mathrm{~min}$ prior to substorm onset and 2 min prior to substorm onset the cross polar-cap potential decreases by approx. $20 \mathrm{kV}$. This would suggest that there is a decrease of plasma flow across the polar-cap immediately prior to substorm onset. The high-latitude plasma flows presented in Fig. 11 also indicate a decrease in the plasma velocity across the polar-cap between 2 min before substorm onset and $2 \mathrm{~min}$ after substorm onset. However, the large error bars associated with these velocities mean that this difference in velocity cannot be judged to be significant. A detailed analysis of the transpolar voltage and high-latitude plasma flows associated with the few minutes immediately prior to and after substorm onset will be an area of further research.

Figure 11 also presents the mean velocity across the dawn and dusk sectors of the polar cap. Although there are only 9 times during the substorm growth and expansion phases where there is a significant difference between the dawn and dusk velocities, at all these times the dusk velocities are significantly larger than the dawn velocities. Figure 13 shows that in the low-latitude return flow the dusk return flow is almost always larger than the dawn return flow. So there appears to be a general trend that the dusk velocity is larger than the dawn velocity, especially at lower latitudes. We wondered whether this difference in the velocity between the dawn and dusk sectors could be due to the radars moving with the rotation of the Earth. In the return flow it would result in faster velocities being observed in the dusk than dawn 
sectors, because the radars would be moving anti-sunward with the rotation of the Earth while the flows are moving sunward. This affect would be more pronounced at lower latitudes. We calculated that at a latitude of $70^{\circ}$ the dusk sector flows should be $300 \mathrm{~ms}^{-1}$ faster than the flows observed in the dawn sectors. We then found that the averaged sunward velocity component for all time sections at a latitude of $70^{\circ}$ was $454 \mathrm{~ms}^{-1}$ in dusk sector and $165 \mathrm{~ms}^{-1}$ in dawn sector, a difference of almost $300 \mathrm{~ms}^{-1}$. Thus, we can conclude that the difference in the velocities in the return flow between the dawn and dusk sectors is due to the rotation of the Earth.

The rotation of the Earth can explain the increase in magnitude in the dusk sector return flow as compared with the dawn flow. However, it does not explain why we sometimes observed higher velocity in the high-latitude anti-sunward flow in the dusk sector than in the dawn sector. While the rotation of the Earth will have less affect on the flow magnitudes observed at higher latitudes, the affect should be to reduce the magnitude of the anti-sunward flow in the dusk sector compared with the dawn sector, as both the plasma and the radars are moving in the same direction with respect to the Earth. Later in this section we will present data proving that the asymmetry in the high-latitude velocities between the dawn and dusk sectors is due to the prevailing IMF conditions.

Figure 14 presents the low-latitude potential within the return flow region from equatorward of the polar-cap boundary to the edge of the radar field-of-view. Comparing Fig. 14 with Fig. 12 it is noted that the average voltage across the low-latitude return flow region is significantly smaller than the average potential across the polar cap. The potential is a measure of how much flux is flowing into or out of the polar cap. Averaged over time we would expect these two values of the potential to be the same. The fact that they are not would suggest that the equatorward edge of the convection zone lies equatorward of the radars' fields-of-view. The convection zone moving to lower latitudes is the most likely cause of the plateau of the low-latitude potential around substorm onset. Parkinson et al. (2003) presented observations of an auroral westward flow channel observed during a substorm by the TIGER SuperDARN radar in the Southern Hemisphere. The auroral flow channel was located at a relatively low latitude of $\sim-65^{\circ}$ in the evening sector, had a width of $\sim 2^{\circ}-3^{\circ}$ latitude and had a maximum westward velocity of $>1.3 \mathrm{kms}^{-1}$ during the expansion phase. We suggest that the strong westward flows observed in this study at the equatorward edge of the radars' $\mathrm{f}-\mathrm{O}-\mathrm{v}$ in the post-dusk sector at, and after, substorm onset could well be the poleward edge of the auroral westward flow channel observed by Parkinson et al. (2003). The Northern Hemisphere SuperDARN radars are clearly not observing the equatorward edge of the flow channel, which would explain the underestimation of the potential across the return flow region.

In this present statistical study IMF information was provided by the ACE spacecraft. The average IMF $B_{y}$ and $B_{z}$ components were negative during the entire substorm interval. The IMF $B_{z}$ component increased (became less nega- tive) before onset, and then decreased slightly at substorm onset. These results agree well with the results of Caan et al. (1978), who performed a statistical study involving superposed epoch averages of the IMF conditions associated with the onset of $\sim 1800$ substorm events from four hours before onset to four hours afterwards. They found that for onsets separated from each other by at least four hours, the average $B_{z}(\mathrm{GSM})$ component was southward for the entire interval. The $B_{z}$ component increased in the $20 \mathrm{~min}$ or so before onset, and then decreased slightly at substorm onset. However, Caan et al. (1978) did not include any calculation of the propagation delay time between the satellite in the solar wind and the magnetopause in their study. Thus, they estimated that the actual delay time between the northward recovery of the IMF and substorm onset was about $10 \mathrm{~min}$ utes. Previous studies have shown that IMF conditions will affect the location of radar backscatter. For example, a study by Provan et al. (1999) on the occurrence of pulsed ionospheric flows as observed by a SuperDARN radar showed the statistical location of such flows to be strongly dependent on the IMF $B_{y}$ component. In order to further investigate the affect of the IMF conditions on the statistical flow patterns, we divided the 67 substorm intervals into two groups depending on the prevailing IMF $B_{y}$ conditions as measured by the ACE spacecraft. Figure $15 \mathrm{a}$ presents the cosine-fitted flow vectors at substorm onset for the substorms which had a negative IMF $B_{y}$ component at this time, Figure $15 \mathrm{~b}$ presents the flow vectors at substorm onset for days which had a positive IMF $B_{y}$ component. Cowley and Lockwood (1992) presented theoretically inferred convection patterns in the Northern Hemisphere under various IMF conditions. The authors stated that during negative IMF $B_{z}$ and $B_{y}$ conditions an oblong "banana" shaped convection cell should be observed in the dusk region and a rounder "orange" shaped cell should be observed in the dawn region. Under negative IMF $B_{z}$ and positive $B_{y}$ conditions the authors inferred that the opposite should be observed with the "banana" shaped cell being observed in the dawn region and the "orange" shaped cell being observed in the dusk region. The results presented in Fig. 15 agree with the work of Cowley and Lockwood (1992). Under negative IMF $B_{y}$ conditions a small "banana" shaped cell can be clearly observed in the dusk region, with a larger round cell being observed in the dawn region. During positive IMF $B_{y}$ conditions the opposite is observed. We can further note that during the negative IMF $B_{y}$ intervals the stronger and more structured high-latitude flows are observed in the noon/pre-midnight region, while during the positive IMF $B_{y}$ intervals the opposite is true with stronger and more structured flows being observed in the dawn/post-midnight region. During the substorms presented in this study the average IMF $B_{y}$ component is predominantly negative, which explains why the high-latitude anti-sunward plasma flows are often stronger in the dusk region as compared to the dawn region. 


\section{Northern hemisphere plasma flow vectors}

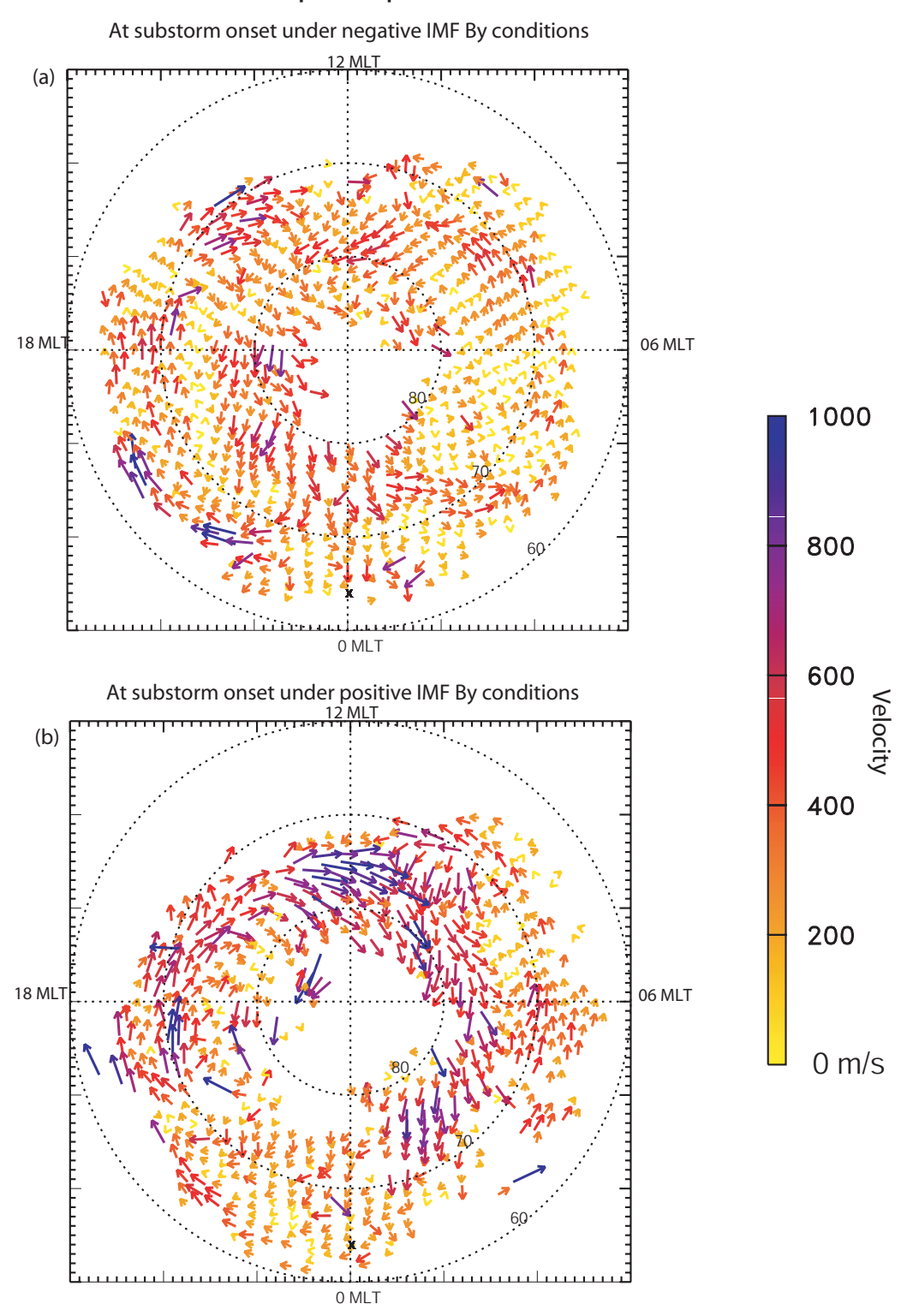

Fig. 15. (a) Cosine-fitted flow vectors at substorm onset for the substorms where onset occurred under negative IMF $B_{y}$ conditions. (b) Cosine-fitted flow vectors at substorm onset for the substorms where onset occurred under positive IMF $B_{y}$ conditions.

\section{Conclusions}

This extensive statistical study has characterised the highlatitude plasma flow during magnetospheric substorms for the first time. Our main observations are:

1. The onset of the substorm growth phase is clearly observed in the radar data 18-20 min before substorm onset, with an increase in the amount of plasma flowing into the polar-cap on the dayside, resulting in an increase in the plasma velocity flowing across the dawn sector of the polar cap, and in the magnetic flux flowing across the dawn-to-dusk polar-cap boundary.
2. During the growth phase the equatorward boundary of nightside radar backscatter moves to lower latitude. We believe this expansion is a result of unbalanced dayside reconnection adding open flux to the polar cap during the growth phase, causing the poleward and equatorward edges of the polar cap to move to lower latitudes (McPherron, 1970).

3. There is evidence that the amount of magnetic flux entering the polar cap decreases in the few minutes prior to substorm onset. This will be an area for further research.

4. At the onset of the substorm expansion phase a suppressed flow region was observed on the nightside, pre- 
midnight of the position of the auroral onset region. We tentatively identify this as the position of the auroral bulge. Faster flows surround this flow suppressed region.

5. At expansion phase onset there is a substantial decline in the occurrence of radar bacskscatter; this decline continues for at least $30 \mathrm{~min}$ after substorm expansion phase onset. This is believed to be due to the nightside precipitation and enhancement of auroral absorption.

6. During both the substorm growth and expansion phases there is dawn-dusk asymmetry in the strength of the low-latitude return flow, with stronger flows being observed in the pre-midnight region. This is due to the radars moving with the rotation of the Earth, with respect to the plasma flow.

7. The dawn-to-dusk polar cap potential increases from $\sim 40 \mathrm{kV} 2$ minutes before substorm onset, to $\sim 75 \mathrm{kV}$ $12 \mathrm{~min}$ after onset. This increase occurs even though the average IMF $B_{z}$ component is increasing (becoming less negative) from $5 \mathrm{~min}$ before substorm onset until $4 \mathrm{~min}$ after substorm onset. This demonstrates that the process of nightside reconnection is driving enhanced flux across the polar cap.

8. The velocities within the low-latitude return flow region start to increase at substorm onset, until $8 \mathrm{~min}$ after substorm onset. Flow across the polar cap reaches a maximum 12-14 min after substorm onset. Thus, nightside reconnection during the substorm expansion phase is adding plasma flux to the polar cap and exciting largescale plasma flow. Enhancement of plasma flow around the nightside flow suppression region may also be partially responsible for the increased velocities.

9. The potential across the low-latitude return flow regions is significantly smaller than the potential across the high-latitude polar-cap region, indicating the equatoward boundary of the convection zone is equatorward of the SuperDARN field-of-view.

10. The observed plasma flow patterns are strongly affected by the prevailing IMF $B_{y}$ conditions, as previously predicted by Cowley and Lockwood (1992). At substorm onset during negative IMF $B_{y}$ conditions the dusk convection cell is small and "banana" shaped, while the dawn convection cell is larger and rounder. The opposite is true during positive IMF $B_{y}$ intervals.

11. The dawn-dusk asymmetry in the strength of the nightside high-latitude equatorward flows are driven by the prevailing negative IMF $B_{y}$ conditions.

This is the first study to prove statistically that nightside reconnection excites high-latitude plasma flow in a similar way to dayside reconnection (Freeman and Southwood, 1988) and that dayside and nightside reconnection are two separate time-dependent processes as predicted by Lockwood et al. (1990) and Cowley and Lockwood (1992).

Acknowledgements. CUTLASS is supported by the Particle Physics and Astronomy Research Council (PPARC grant PPA/R/R/1997/00256). U.K., the Swedish Institute for Space Physics, Uppsala, and the Finnish Meteorological Institute. Helsinki. GP is supported by PPARC grant PPA/G/O/2001/00014. The IMAGE FUV program was supported through SWRI subcontract number 83820 by NASA under contract number NAS5-96020.

Topical Editor T. Pulkkinen thanks M. Freeman and another referee for their help in evaluating this paper.

\section{References}

Caan, M. N., McPherron R. L., and Russell C. T., : The statistical magnetic signature of magnetospheric substorms, Planet. Space Sci., 26, 269-279, 1978.

Cowley, S. W. H. and Lockwood M.: Excitation and decay of solar wind-driven flows in the magnetosphere-ionosphere system, Ann. Geophys., 10, 103-115, 1992.

Cowley, S. W. H, Davies, J. A., Grocott, A., Khan H., Lester M., McWilliams, K. A., Milan, S. E., Provan G., Sandholt, P. E., Wild J. A. and T. K. Yeoman : Solar-wind-magnetosphere-ionosphere interactions in the Earth's plasma environment, Phil. Trans. R. Soc. Lond. A (2003) 361, 113-126, 2002.

Dungey, J. W.: Interplanetary field and the auroral zones, Phys. Res. Lett., 47-48, 1961.

Fox, N. J., Cowley, S. W. H., Davies, J. A., Greenwald, R. A., Lester, M, Lockwood,M, and Lühr, H.: Ionospheric ion and electron heating at the poleward boundary of a poleward expanding substorm-disturbed region. J. Geophy. Res., 106, 12 845-12 862, 2001.

Freeman, M. P. and Southwood, D. J.: The effect of magnetospheric erosion on mid- and high-latitude ionospheric flows, Planet Space Sci., 36, 509, 1988.

Gibson, W. C., Burch, J. L., Sherrer, J. R. et al.: The IMAGE Observatory, Space Sci. Rev., 91, 15-51, 2000.

Grafe, A, Pellinen, R. J., Baumjohann, W., and Vallinkoski, M.: Development of the auroral electrojets on March 16 1978: an event study, Ann. Geophys., 23, 11, 1987.

Greenwald, R. A., Baker, K. B., Dudeney, J. R. et al.: DARN/SUPERDARN A global view of the dynamics of highlatitude convection, Space Sci. Rev., 71, 761-796, 1995.

Grocott, A, Cowley, S. W. H., Sigwarth, J. B., Waterman, J. F., and Yeoman, T. K.: Excitation of twin-vortex flow in the nightside high-latitude ionosphere during an isolated substorm, Ann. Geophys., 20, 1577-1601, 2002.

Heppner, J. P. and Maynard N. C.: Empirical high-latitude electric field models, J. Geophys. Res., 92, 4467-4489, 1987.

Khan, H., Cowley, S. W. H., Kolesnikova, E., Lester, M., Brittnacher, M. J., Hughes, T. J., Hughes, W. J., Kurth, W. S., McComas, D. J., Newitt, L., Owen, C. J., Reeves, G. D., Singer, H. J., Smith, C. W., Southwood, D. J., and Watermann, J. F.: Observations of two complete substorm cycles during the Cassini Earth swing-by: Cassini magnetometer data in a global context, J. Geophys. Res., 106, 30 141-30 175, 2001.

Lester, M., de la Beujardière, O., Foster, J. C., Freeman, M. P., Lühr, H., Ruohoniemi, J. M., and Swider, W.: The response of the large-scale ionospheric convection pattern to changes in 
the IMF and substorms: Results from the SUNDIAL 1987 campaign, Ann. Geophys., 11, 556-571,1993.

Lester, M.: HF coherent scatter radar observations of ionospheric convection during magnetospheric substorms, Adv. in Polar Upper Atmosphere Research, 12, 179, 2000.

Lewis, R. V., Freeman, M. P., Rodger, A. S., Reeves, G. D., and Milling, D. K.,:The electric field response to the growth phase and expansion phase onset of a small isolated substorm, Ann. Geophys., 15, 289, 1997

Lockwood, M., Cowley, S. W. H., and Freeman, M. P.: The excitation of plasma convection in the high-latitude ionosphere, J. Geophys. Res., 95, 7961-7972, 1990.

Lockwood, M.: On flow reversal boundaries and cross-cap potential in average models of the high latitude convection, Planet. Space Sci., 39, 397, 1991.

Lui, A. T. R.: A synthesis of magnetospheric substorm models, J. Geophys. Res., 96, 1849-1856, 1991.

McPherron, R. L.: Growth phase of magnetospheric substorms, J. Geophys. Res., 75, 5592, 1970.

Mende, S. B., Heetderks, H., Frey, H. U. et al.: Far ultraviolet imaging from the IMAGE spacecraft, Space Sci. Rev., 91, 243-287, 2000 .

Mende, S. B., Carlson, C. W., Frey, H. U., Peticolas, L. M., Østgaard, N,.: FAST and IMAGE-FUV observations of a substorm onset ,J. Geophys. Res., 108, A9, 1344,10.1029/2002JA009787, 2003.

Milan, S. E., Jones, T. B., Lester, M., Warrington, E. M., and Reeves, G. D.: Substorm correlated absorption on a $3200 \mathrm{~km} \mathrm{HF}$ propagation path, Ann. Geophys., 13, 182-190, 1996.

Milan, S. E., Davies, J. A., and Lester, M.: Coherent HF radar backscatter characteristics associated with auroral forms identified by incoherent radar techniques: a comparison of CUTLASS and EISCAT observations, J. Geophys. Res., 104, 22 591-22 604, 1999.

Milan, S. E., Lester, M., Cowley, S. W. H., Oksavik, K., Brittnacher, M., Greenwald, R. A., Sofko, G., and Villain, J.-P.: Variations in polar cap area during two substorm cycles, Ann. Geophys., 21, 1121-1140, 2003.

Morelli, J. P., Bunting, R. J., Cowley, S. W. H., Farrugia, C. J., Freeman, M. P., Friis-Christensen, E., Jones, G. O. L., Lester, M., Lewis, R. V., Lühr, H., Orr, D., Pinnock, M., Reeves, G. D., Williams, P. J. S., and Yeoman, T. K.: Radar observations of auroral zone flows during multiple onset substorm, Ann. Geophys., 12, 1144, 1995.

Opgenoorth, H. J. and Pellinen, R. J.: The reaction of the global convection electrojets to the onset and expansion of the susbtorm current edge, in : "Substorms-4" (Eds.) by Kokubun, a and Kamide, Y, Terra Sci. Publ. Co., Tokyo, 663, 1998.

Parkinson, M. L., Pinnock, M., Ye, H., Hairston, M. R., Devlin, J. C, Dyson, P. L, Morris, R. J, Ponomarenko, P.: On the lifetime and extent of an auroral westward flow channel (AWFC) observed during a magnetospheric substorm, Ann. Geophys.,21, 893-913, 2003.
Petrukovich, A. A., Sergeev, V. A., Zleneyi, L. M., Mukai, T., Yamamoto, T., Kokubun, S., Shiokawa, K., Deehr, C. S., Budnick, E. Y., Büchner, J., Fedorov, A. O., Grigorieva, V. P., Hughes, T. J., Pissarenko, N. F., Romanov, S. A., and Sandahl, I.: Two spacecraft observations of a reconnection pulse during an auroral breakup, J. Geophys. Res., 103, 47, 1998.

Provan, G., Yeoman, T. K., and Cowley, S. W. H.: The influence of the IMF By on the location of pulsed flows in the dayside ionosphere observed by the HF radars, Geophys. Res. Lett., 26, 521-524, 1999.

Provan, G., Yeoman, T. K., Lester, M., and Milan, S. E.: A multiinstrument approach to mapping the global dayside merging gap, Ann. Geophys.,20, 1905-1920, 2002.

Ruohoniemi, J. M., and Greenwald, R. A.: Statistical patterns of high-latitude convection obtained from the Goose Bay HF radar observations.J. Geophys. Res., 101, 21 743-21 763, 1996.

Ruohoniemi, J. M. and Baker, K. B.: Large-scale imaging of highlatitude convection with Super Dual Auroral Radar Network HF radar observations, J. Geophys. Res., 103, 20 797-20 811, 1998.

Russell, C. T.: The configuration of the magnetosphere in Critical Problems of Magnetospheric Physics, E. R. Dyer, Inter-Union Committee on STP, National Academy of Sciences, Washington DC, 1-16, 1972.

Russell, C. T. and McPherron, R. L.: Semi-annual variation of Geomagnetic Activity, J. Geophys. Res., 78, 92-108, 1973.

Sandholt, P. E., Farrugia, C. J., Lester, M, Cowley, S. W. H., Milan, S. E, Denig, W. F., Lybekk, B., Trondsen, E., and Vorobjev, V.: Multistage substorm expansion: Auroral dynamics in relation to plasma sheet particle injection, precipitation, and plasma convection, J. Geophys. Res., 107 (A11): art. no. 1342, 2002.

Siscoe, G. L. and Huang, T. S.: Polar cap inflation and deflation, J. Geophys. Res., 90, 543-547, 1985.

Weimer, D. R.: Models of high-latitude electric potentials derived with a least error fit of spherical harmonic coefficients, J. Geophys. Res., 100, 19595-19607, 1995.

Yeoman, T. K. and Lühr, H.: CUTLASS/IMAGE observations of the high-latitude convection features during substorms, Ann. Geophys, 15, 692, 1997.

Yeoman, T. K., Lewis, R. V., Milan, S. E. and Watanabe M.: An interhemispheric study of the ground magnetic and ionospheric electric fields during the substorm growth and expansion phase onset, J. Geophys. Res., 104, 14 867, 1999.

Yeoman, T. K., Davies, J. A., Wade, N. M., Provan, G., and Milan, S. E.: Combined CUTLASS, EISCAT and ESR observations of ionospheric plasma flows at the onset of an isolated substorm, Ann. Geophys., 18, 1073-1087, 2000a.

Yeoman, T. K., Khan H., Cowley, S. W. H., Lewis, R. V., and Ruohoniemi, J. M.: Interhemispheric HF radar observations of nightside ionospheric convection in response to IMF Bz and By changes and substorm pseudobreakup Proc. ICS-5, ESA SP-443, 103-106, 2000b. 